Article

\title{
Comparative Analysis of two Sugarcane Ancestors Saccharum officinarum and S. spontaneum based on Complete Chloroplast Genome Sequences and Photosynthetic Ability in Cold Stress
}

\author{
Fu Xu ${ }^{1,2}$, Lilian $\mathrm{He}^{1}$, Shiwu Gao ${ }^{2}$, Yachun Su ${ }^{2}$, Fusheng $\mathrm{Li}^{1,2, *}$ and Liping $\mathrm{Xu}^{2, *}$ \\ 1 College of Agronomy and Biotechnology, Yunnan Agricultural University, Kunming 650201, China \\ 2 Key Laboratory of Sugarcane Biology and Genetic Breeding, Fujian Agriculture and Forestry University, \\ Fuzhou 350002, China \\ * Correspondence: lfs810@sina.com (F.L.); xlpmail@126.com (L.X.); Tel.: +86-871-6522-0502 (F.L.); \\ +86-591-8377-2604 (L.X.)
}

Received: 7 July 2019; Accepted: 2 August 2019; Published: 5 August 2019

Abstract: Polyploid Saccharum with complex genomes hindered the progress of sugarcane improvement, while their chloroplast genomes are much smaller and simpler. Chloroplast (cp), the vital organelle, is the site of plant photosynthesis, which also evolves other functions, such as tolerance to environmental stresses. In this study, the cp genome of two sugarcane ancestors Saccharum officinarum and S. spontaneum were sequenced, and genome comparative analysis between these two species was carried out, together with the photosynthetic ability. The length is 141,187 bp for S. officinarum and that is 7 bp longer than S. spontaneum, with the same GC content $(38.44 \%)$ and annotated gene number (134), 13 with introns among them. There is a typical tetrad structure, including LSC, SSC, IRb and IRa. Of them, LSC and IRa/IRb are $18 \mathrm{bp}$ longer and $6 \mathrm{bp}$ shorter than those in S. spontaneum (83,047 bp and 22,795 bp), respectively, while the size of SSC is same (12,544 bp). Five genes exhibit contraction and expansion at the IR junctions, but only one gene $n d h F$ with $29 \mathrm{bp}$ expansion at the border of IRb/SSC. Nucleotide diversity (Pi) based on sliding window analysis showed that the single copy and noncoding regions were more divergent than IR- and coding regions, and the variant hotspots trnG-trnM, psbM-petN, trnR-rps14, ndhC-trnV and petA-psbJ in the LSC and $\operatorname{trn} L-c c s A$ in the SSC regions were detected, and $p e t A-p s b J$ with the highest divergent value of 0.01500 . Genetic distances of 65 protein genes vary from 0.00000 to 0.00288 between two species, and the selective pressure on them indicated that only pet $B$ was subjected to positive selection, while more genes including $r p o C 2, r p s 3, c c s A, n d h A, n d h A, p s b I$, atpH and $p s a C$ were subjected to purifying or very strong purifying selection. There are larger number of codons in S. spontaneum than that in S. officinarum, while both species have obvious codon preference and the codons with highest-(AUG) and lowest frequency (AUA) are same. Whilst, the most abundant amino acid is leucine in both S. officinarum and S. spontaneum, with number of 2175 (10.88\% of total) and 2228 (10.90\% of total) codons, respectively, and the lowest number is cysteine, with only 221 (1.105\%) and 224 (1.096\%), respectively. Protein collinearity analysis showed the high collinearity though several divergences were present in cp genomes, and identification of simple sequence repeats (SSRs) were included in this study. In addition, in order to compare cold tolerance and explore the expanding function of this environmental stress, the chlorophyll relative content (SPAD) and chlorophyll fluorescence Fv/Fm were measured. The significantly higher SPAD were observed in S. spontaneum than those in S. officinarum, no matter what the control conditions, exposure to low temperature or during recovery, and so was for $\mathrm{Fv} / \mathrm{Fm}$ under exposure to low temperature, together with higher level of SPAD in S. spontaneum in each measurement. Aforementioned results suggest much stronger photosynthetic ability and cold tolerance in S. spontaneum. Our findings build a foundation to investigate the biological mechanism of two sugarcane ancestor chloroplasts and retrieve reliable 
molecular resources for phylogenetic and evolutionary studies, and will be conducive to genetic improvement of photosynthetic ability and cold resistance in modern sugarcane.

Keywords: sugarcane ancestors; chloroplast genome; genome comparative analysis; cold stress; chlorophyll relative content; chlorophyll fluorescence

\section{Introduction}

Chloroplast, the vital organelle, is the site of plant photosynthesis. Generally, for most photosynthetic organisms, chloroplast ( $\mathrm{cp}$ ) genomes range from $115 \mathrm{~kb}$ to $165 \mathrm{~kb}$ in size [1-3]. The $\mathrm{cp}$ genomes are conventionally described as a circular DNA, consisting of a quadripartite structure of one large single-copy (LSC) region, two inverted repeat (IRa and IRb) regions, and one small single-copy region (SSC) [4]. Their sequence, organization, gene content and gene order are considered to be well conservative due to an absence of genetic recombination [5-7], though there are mutation events, insertions and deletion, pseudogenes or structural gene rearrangements occurrence in some lineages [2,8-11], the mutation rate is low. Additionally, substitution and base insertion or deletion are the main mutation types. Hence, the cp genome sequence has been used in phylogenetic and evolutionary analysis, identification of SSRs and SNPs, and development of plant barcoding [12-17], and defining species limits [18].

Sugarcane, which has been cultivated in more than 100 countries, is the most important sugar crop accounting for more than $78 \%$ of the total world sugar production. The 'noble' species Saccharum officinarum and the wild S. spontaneum are valuable resources which contributes respectively sugar, and biotic and abiotic stress resistance, and growth vigor. These two species belong to the genus Saccharum, which contains six different species including S. officinarum, S. spontaneum, S. sinense, S. barberi, S. robustum and S. edule. Among them, S. officinarum and S. spontaneum are thought to be the ancestors of modern cultivated sugarcane [19], of which $70-80 \%$ from S. officinarum, 10-20\% from S. spontaneum and about $10 \%$ from interspecific recombination [20]. Thus, the genomic structure of modern sugarcane hybrids is recognized to have homologous interspecific and intraspecific chromosomes [21], while S. sinense and S. barberi are regarded as interspecific hybrids between S. officinarum and S. spontaneum [19], which resulting in an exceedingly complex interspecific polyploid sugarcane genome. Due to the complexity in ploidy, the complete genome of modern sugarcane is still remaining to be deciphered though great progress has been made by drawing allele-defined genome of tetraploid S. spontaneum AP85-441 [22], and by assembling a mosaic monoploid reference sequence for modern sugarcane cultivar R570 based on bacterial artificial chromosome (BAC) clones [23]. One common characteristic is their multiple chromosome numbers in the different species and even in the same species of the genus Saccharum, which normally is thought to be $2 \mathrm{n}=80$ for original accessions of S. officinarum, in spite of different opinions referring to $S$. officinarum can be found, which including $2 \mathrm{n}=70$ to 140 for S. officinarum [24] and the controversial basic chromosome number $(x=8$ or 10) $[25,26]$. Both the homogenous polyploid nature and the large variation of chromosome number in the genus Saccharum and in the specie S. spontaneum, whose chromosome number ranges from 40 to 128 and ploidy from $4 \times$ to $12 \times[20,24]$, have increased its difficulty in genome assembling and gene annotation, together with the analysis of their phylogeny. The complex genome of modern sugarcane hinders the progress of its improvement, while their chloroplast genomes are much smaller and relatively simpler, thus, study on sugarcane genome can aid to promote sugarcane improvement, especially in molecular marker selection.

The first complete sugarcane chloroplast genome was obtained from modern hybrid NCo310 by CEQ Dye Terminator Cycle Sequencing [27], and soon after that, the cp genome of sugarcane hybrid SP80-3280 by shotgun sequencing was obtained [28]. Both carried out a comparative analysis with monocot wheat, rice, and maize chloroplast genomes by focusing on the genes at the $r p s 16-\operatorname{trn} Q$ and 
the $t r n S-t r n C$ regions, respectively, to identify the divergences and polymorphisms. Recently, the complete cp genome of sugarcane hybrid Q155 [6] and RB867515 [29] were obtained, and their main focuses are on identification of polymorphic sites, insertion and deletion events by comparing Q155 with NCo310 and SP80-3280 [6], and RB867515 with Q155, NCo310 and SP80-3280 [29], respectively. All of these studies focused on sugarcane hybrids. More recently, focusing on sugarcane origins from the plastid view was reported by comparing their complete cp genomes of S. spontaneum, S. officinarum and Miscanthus floridulus [30]. However, an understanding of the structure variation, identification of highly divergent regions, analysis of coding protein genes and single nucleotide polymorphic loci in cp genomes between the crucial species, i.e., two ancestor species S. officinarum and S. spontaneum of modern sugarcane cultivars, is very limited, and needs to be elucidated in more detail.

Plants perform photosynthesis in the chloroplast, which is known as the vital organelle, to acquire energy for growth and development. Whilst, in addition to this crucial function, it also evolves to extend functions, such as tolerance to environmental stresses of drought, temperature extreme, high salinity and alkali, high light strength, ultraviolet radiation and heavy metals [2,31-36]. Recently, chloroplast acting as a sensor of environmental signals and playing a key role in the construction of plant immunity were suggested by Serrano et al. [37]. However, the response of sugarcane chloroplasts to environmental stresses is remained to be revealed. Temperature is a critical factor which profoundly affects plant growth, development, and geographical distribution [38-40]. Sugarcane originates from tropical regions and is currently mainly cultivated in subtropical regions, such as Queensland in Australia, San Paulo in Brazil, Guangxi in China, after long-term domestication. However, it usually suffers from a serious effect on yield and quality due to its weak cold tolerance when exposed to low temperature [41], and frequency changes of climate in recent years aggravate the effects of low temperature on sugarcane industry. Fortunately, the sensitivity to cold varies widely among sugarcane germplasms [42].

S. officinarum and S. spontaneum in Saccharum are two ancestor species of modern sugarcane cultivars or hybrids. Two accessions of Badila and Yunnan 83-184 are the clones belonging to S. officinarum and S. spontaneum, respectively. Among them, Badila is also used as a cultivar for chewing cane (not for making sugar) although it is an original or primitive cultivar. In this study, we (1) obtained the complete chloroplast genome sequences of S. officinarum and S. spontaneum; (2) carried out the comparative cp genomics between the 'noble' species $S$. officinarum and wild species $S$. spontaneum; (3) elucidated their structure variation, identified the highly divergent regions, compared coding protein genes and estimated their genetic distances, and identified single nucleotide polymorphism (SNP) loci. Additionally, the photosynthetic parameters of SPAD (chlorophyll relative content) and $\mathrm{Fv} / \mathrm{Fm}$ (variable chloroplast fluorescence/maximal chloroplast fluorescence) in control (before exposed to stress), low temperature and during recovering in field conditions were investigated.

\section{Results}

\subsection{Quality and Quantity of Raw Data and Clean Data Obtained from Sequencing}

Using the Illumina HiSeq 2500 system, 5,701,229,700 and 5,343,719,700 base-pairs of clean data were generated from S. officinarum and S. spontaneum, respectively, and their reads reach $519 \times$ and $316 \times$ coverage over the two cp genomes, respectively. Among them, 19,004,099 and 17,812,399 paired-end reads after filtering artificial sequences and low-quality reads $(\leq \mathrm{Q} 20$ bases) were obtained in S. officinarum and S. spontaneum, respectively. The high quality of raw data is indicated by the $92.83 \%$ and $93.03 \%$ of $\geq Q 30$ bases in clean reads in S. officinarum and S. spontaneum, respectively. Before assembling, chloroplast DNA (cpDNA) sequences were drawn by aligning with the database of plant cp genomes. Only those matched the cp sequences in this database can be used for genome assembling, which are 262,149 reads for S. officinarum and 174,306 reads for S. spontaneum. The histograms of insert sizes for both species were shown in Figure S1, and the average insert size is $303.7 \mathrm{bp} \pm 69.4 \mathrm{bp}$ for S. officinarum, and $310.6 \mathrm{bp} \pm 70.7 \mathrm{bp}$ for $S$. spontaneum. The ambiguous nucleotide sites in the cp genome, 
produced in the scaffold extension step during de novo assembly, were corrected manually. The errors relevant to heterogeneous Indels (i.e., insertions/deletions) caused from homopolymeric repeats in the genome were also corrected. To test the quality of assembly of the cp genomes of S. officinarum and S. spontaneum, three steps including: (1) using assembled genome as reference, statistical genome coverage, insert fragment size, etc.; (2) genome alignment with the reference sequence (NCBI accession: LS975131.1) to check conservation and rearrangement; (3) alignment with the reference for structure information. The final sequences of complete cp genomes for S. officinarum and S. spontaneum will be deposited in GenBank, and their corresponding accession numbers are MN204507 and MN204508, respectively, and they will be released on January 26, 2020.

\subsection{Chloroplast Genomic Structure and Gene Diversification}

The size of the cp genome for S. officinarum is $141,187 \mathrm{bp}$, and that is $141,181 \mathrm{bp}$ for S. spontaneum, while the GC content (38.44\%) is completely the same. The coverage map for assembly chloroplast sequence genomes were showed in Figure 1, which can help to distinguish the coding genes (CDS), tRNA, rRNA, the coverage depth and GC content of the genome. The gene maps of the complete circle chloroplast genomes of S. officinarum (A) and S. spontaneum (B) are shown in Figure 2. In the $\mathrm{cp}$ genome of $S$. officinarum, there is a typical tetrad structure, including the sequences of paired IRA and IRB, which encode in opposite directions, and so is in the species S. spontaneum. In addition, there are large and small single copy regions in both $\mathrm{cp}$ genomes. The length of the large single copy (LSC) region is 83,065 bp with base sequence position from 1 to 83,065 , the small single copy (SSC) region is $12,544 \mathrm{bp}$ (from position 105,855 to 118,398) and both the two inverted repeat (IR) regions are 22,789 bp in S. officinarum, of which IRa from position 118,399 to 141,187, and IRb from position 83,066 to 105,854 . Among these regions, LSC and IR are 18 bp larger and 6 bp shorter than those in $S$. spontaneum ( $83,047 \mathrm{bp}$ and 22,795 bp), respectively. Gene annotation showed that there were 134 annotated genes in cp genome of S. officinarum and S. spontaneum, which is one less than that in cp genome of Saccharum hybrid cultivar RB867515 (135) [29]. The gene numbers for all of the mRNA/protein coding genes (CDS) (88), tRNA (38) and rRNA (8) are same in two different species, with 40 duplicated genes in the IR region, while both lacking one tRNA gene compared to the modern cultivar RB867515 (39) [29]. In addition, the unique gene numbers of CDS, tRNA and rRNA are same in both species. Among the CDS genes, there are 12 genes have introns in both species, of which only one gene ycf3 with two introns, the other 11 genes including atpF, $n d h A, n d h B, r p l 2, r p s 16$, trnL-UUU, trnS-CGA, trnL-UAA, trnA-UGC, trnV-UAC, trnT-CGU with one intron. Additionally, there are two introns in the gene rps12 but with a trans-splicing, and thus not counted in our statistic in this study, due to the start sites of both introns are located in the IR region, in spite of sometimes the aforementioned introns indeed having been counted, such as in the study of Mikania [7]. Exons existed in all 134 genes, of which most (116) have only one-, 14 genes have two-, and only three genes (ycf3 and two rps12) have three exons. In the IR region, there are 20 genes with two or more copies: $n d h B, r p l 2, r p l 23, r p s 12, r p s 15, r p s 19, r p s 7, r r n 16, r r n 23, r r n 4.5, r r n 5, t R N A-A C G, t R N A-C A A$, tRNA-CAU, tRNA-CAU, tRNA-CGU, tRNA-GAC, tRNA-GUG, tRNA-GUU, tRNA-UGC, ycf1 and ycf2, of which the gene rpl2 with three copies and $t R N A-C A U$ with four copies. These characteristics and the number of exons and introns are same in two different species while the positions in the cp genome are divergent for most of exons and introns, in spite of the lengths are same for vast majority, and only two introns with different lengths. Of which, two introns with different length were located in the gene ycf3: $780 \mathrm{bp}$ and $736 \mathrm{bp}$ in size for S. officinarum, while $754 \mathrm{bp}$ and $737 \mathrm{bp}$ in size for S. spontaneum, respectively. Additionally, the intron in $t R N A-U U U$ of $S$. officinarum is $2475 \mathrm{bp}$ in size, one base-pairs less compared to that in S. spontaneum. Both species have four different types of hypothetical or putative chloroplast genes, including five genes (two $y c f 1$, two $y c f 2$ and one $y c f 3$ gene) existed in the IR region and one gene $p s b J$ existed in the other region. Besides, there is one undefined function gene rpl2 in two species. Details were presented in supplementary Table S1 (Saccharum_officinarum.exon.intron.stat) and Table S2 (Saccharum_spontaneum.exon.intron.stat). The coding protein genes (88) can be divided 
into four categories: (1) self-replicating genes; (2) photosynthesis genes including light systems I and II, adenosine-triphosphate (ATP) synthase, a cytochrome b6/f protein complex and other biosynthesis genes, such as cytochrome related genes; (3) other genes, including those genes related to biosynthesis; (4) Unknown function protein-coding gene. Details of the gene contents, including gene family, their functions and gene names, in the cp genomes of two sugarcane ancestors were presented in Table 1.

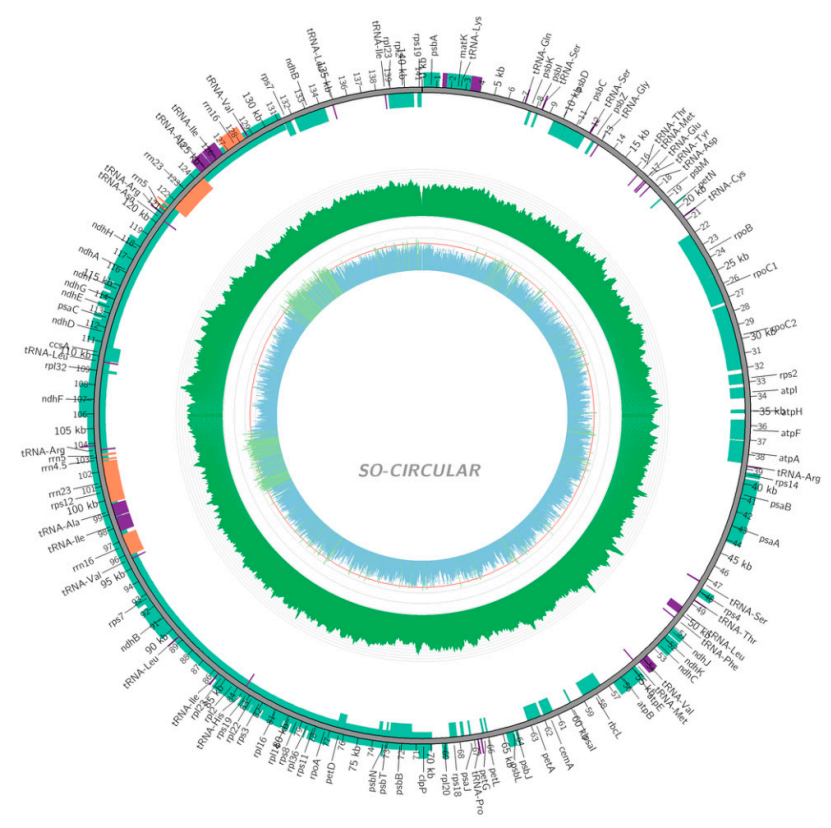

A: SO-CIRCULAR

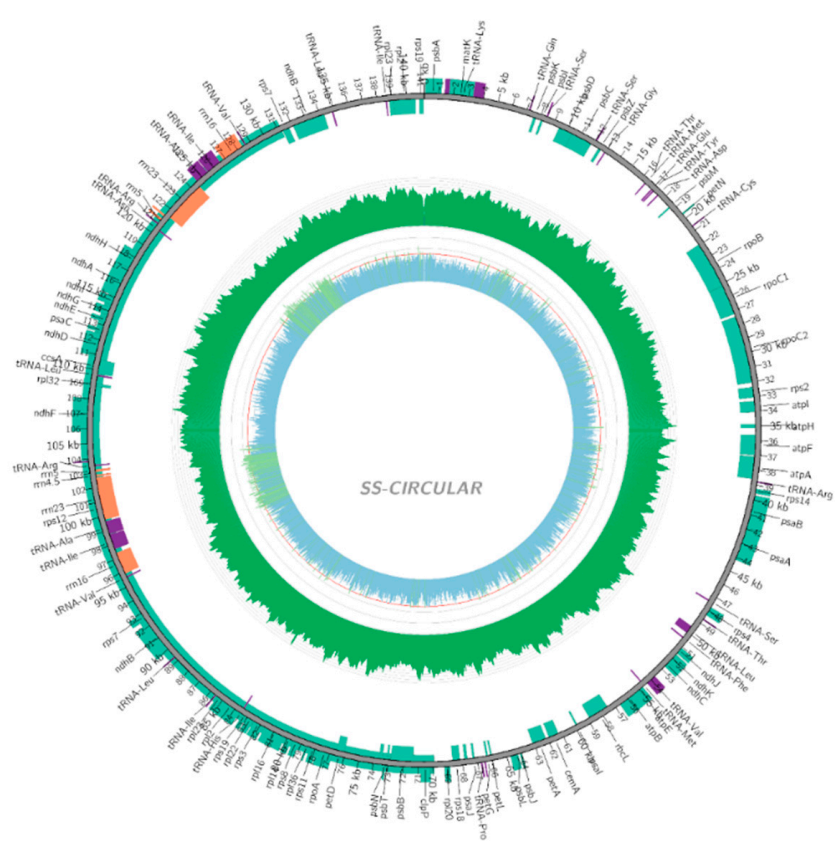

B: SS-CIRCULAR

Figure 1. Coverage map for assembly chloroplast sequence genomes of Saccharum officinarum (A) and S. spontaneum (B). Outermost circle: genome sequence. Green box: the coding genes; Purple box: tRNA; Orange box: rRNA; Green ring: the coverage depth, of which reverse repeat area is generally two times than that of other areas; Inner circle: GC content of the genome, of which green line representing greater than $50 \%$, and blue for smaller than $50 \%$. 

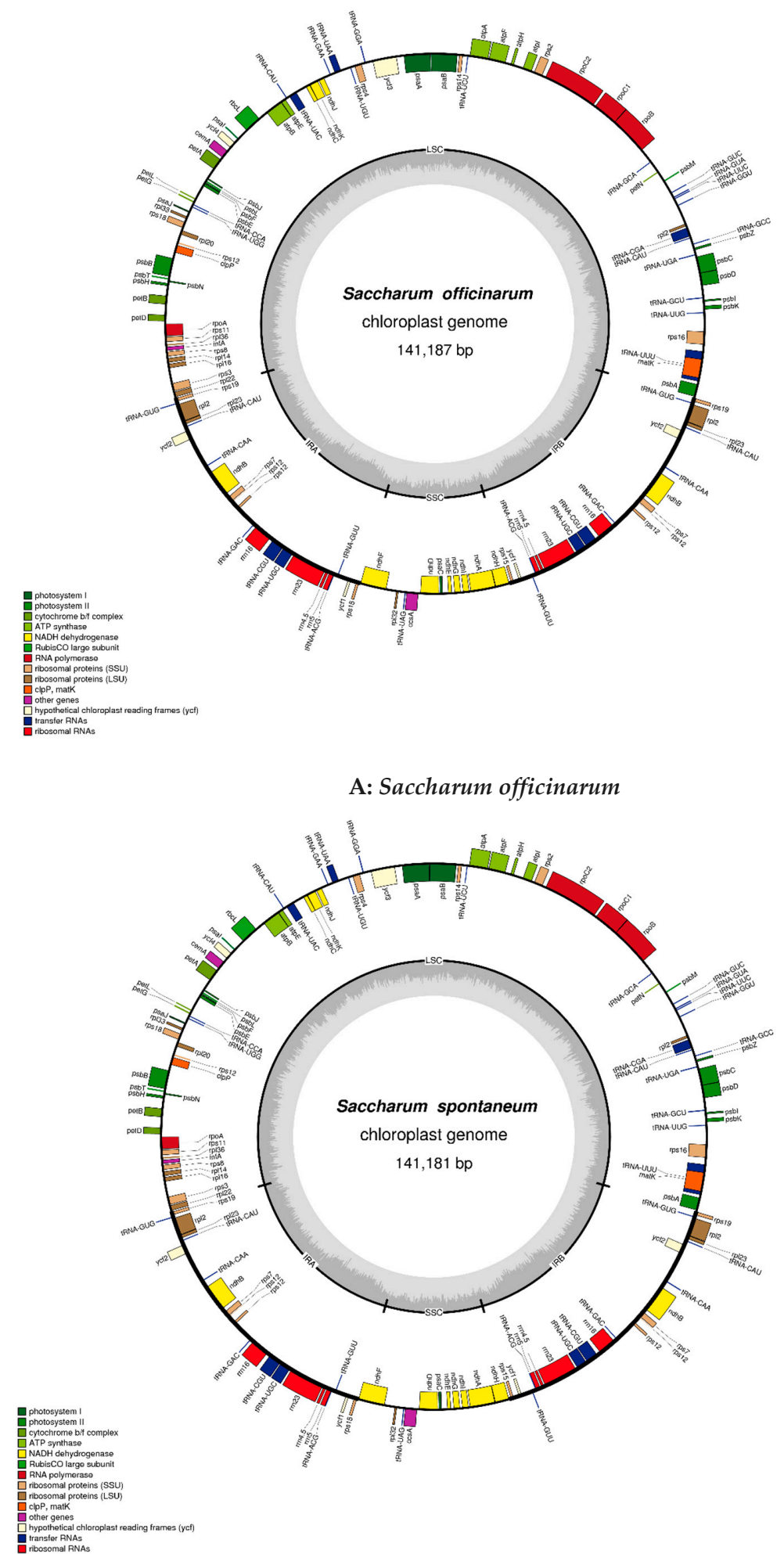

B: Saccharum spontaneum

Figure 2. Gene maps of the complete chloroplast genome of Saccharum officinarum (A) and S. spontaneum (B) generated by software OGDRAW. As indicated in Figure 2, genes located outside of the outer circle are transcribed in the counterclockwise direction, while those located inside are transcribed in the clockwise direction. Different functional gene groups are represented in color codes. In addition, the variations of GC and AT content are indicated by lighter gray and darker gray plot in the inner circle, respectively. 
Table 1. Gene contents in the chloroplast genomes of Saccharum officinarum and S. spontaneum.

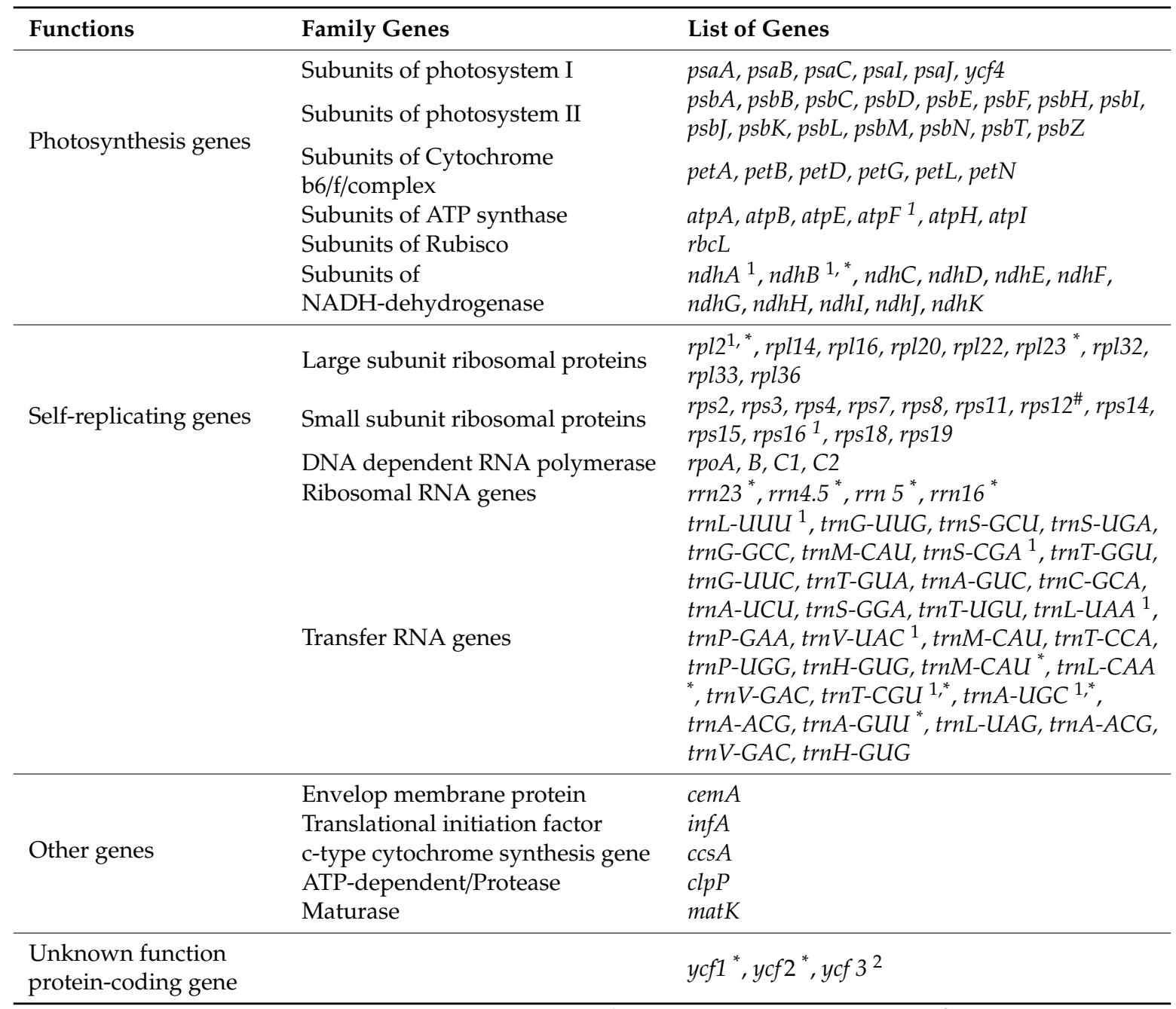

Notes: * Two gene copies in IRs; \# Trans-splicing gene; ${ }^{1}$ Gene containing a single intron; ${ }^{2}$ Gene containing two introns.

\subsection{The Collinear Analysis}

The collinear analysis by Mauve software revealed the highly conserved structures of two sugarcane ancestors, thus the high collinearity was observed between S. officinarum var. Badila and S. spontaneum var. Yunnan 83-184, no matter which types of genes. However, there still are some sites containing insertions and deletions in their cp genomes (Figure 3). For example, one CDS gene near the site of 20,000, there appeared deletions in size in S. spontaneum, while two genes between the sites of 50,000 and 55,000 appeared insertions in S. spontaneum. It is interesting to note that two CDS genes between the sites of 65,000 and 70,000 on the positive chain appeared to be contrary in these two species when referring to the size, which is one deleted while the other inserted. 


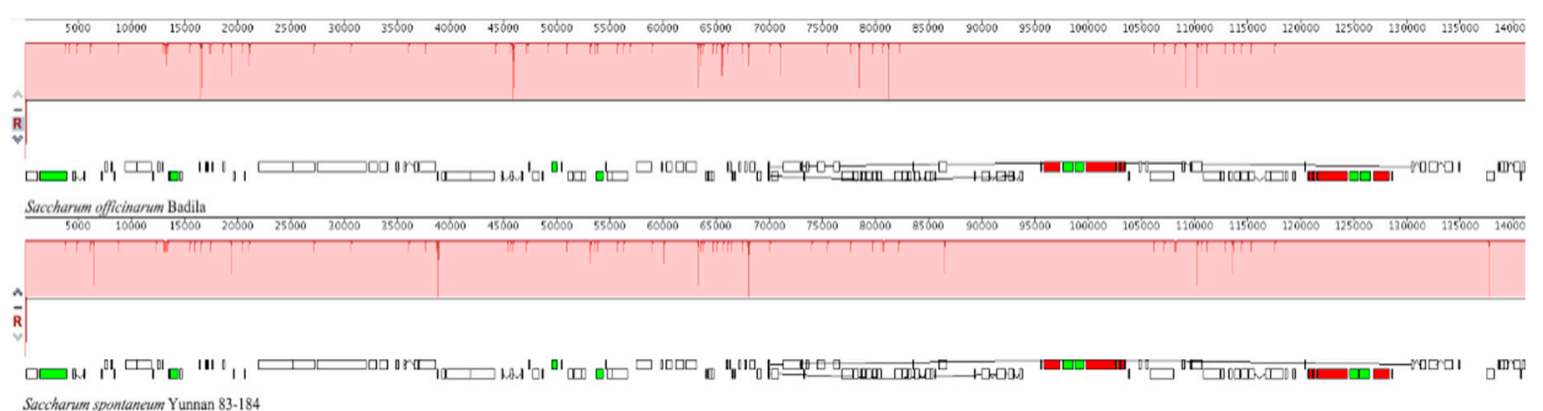

Figure 3. Colinear analysis of chloroplast genomes between two sugarcane ancestors Saccharum officinarum and S. spontaneum. Color bands represent genes, and different colors represent different blocks. Blocks with the same color between different genes represent homologous regions. Within each block, Mauve software draws similar profiles of genome sequences, and the height of similar profile corresponds to the average conservative level of the sequence region of the genome. Two rows of small blocks below the color band represent genes. The top one is on the positive chain, and the below one is on the complementary chain. Of which, the white block represents the CDS, a thin line inside the white blocks denotes intron. Green and red blocks represent tRNA and rRNA, respectively.

\subsection{Analysis of Highly Variable Regions and Base Substitutions in CDS Genes}

In spite of extreme similarities in the structure and organization in cp genomes of two sugarcane ancestors S. officinarum and S. spontaneum, the divergences may also exist in the noncoding regions, especially in the regions of intergenic sequence (IGS). Thus, we further investigated the level of divergence by analysis of nucleotide variability (Pi). In the aligned cp genomes of two different species, Pi obtained by sliding window analysis indicated the locations of the variation occurring. The values of Pi range from 0.000 to 0.01500 , and those with the percentage of variation higher than 0.00600 $(\mathrm{Pi}>0.006)$ were marked out from a total of 129 divergent genes (Figure 4). According to this Pi value, six of the most variable sites were detected between the two species, of which five in the LSC region, namely $\operatorname{trn} G$-trnM, psbM-petN, trnR-rps14, ndhC-trnV and petA-psbJ, together with one site named $\operatorname{trnL}-\operatorname{ccs} A$ in the SSC region, while non-site meets the standard in the IR region, indicating the very conservative IRs in both genomes. Additionally, the percentages of variation among the divergent genes are 0.00167 , and the gene of petA-psbJ in the LSC region was found to have the highest divergent value of 0.01500 .

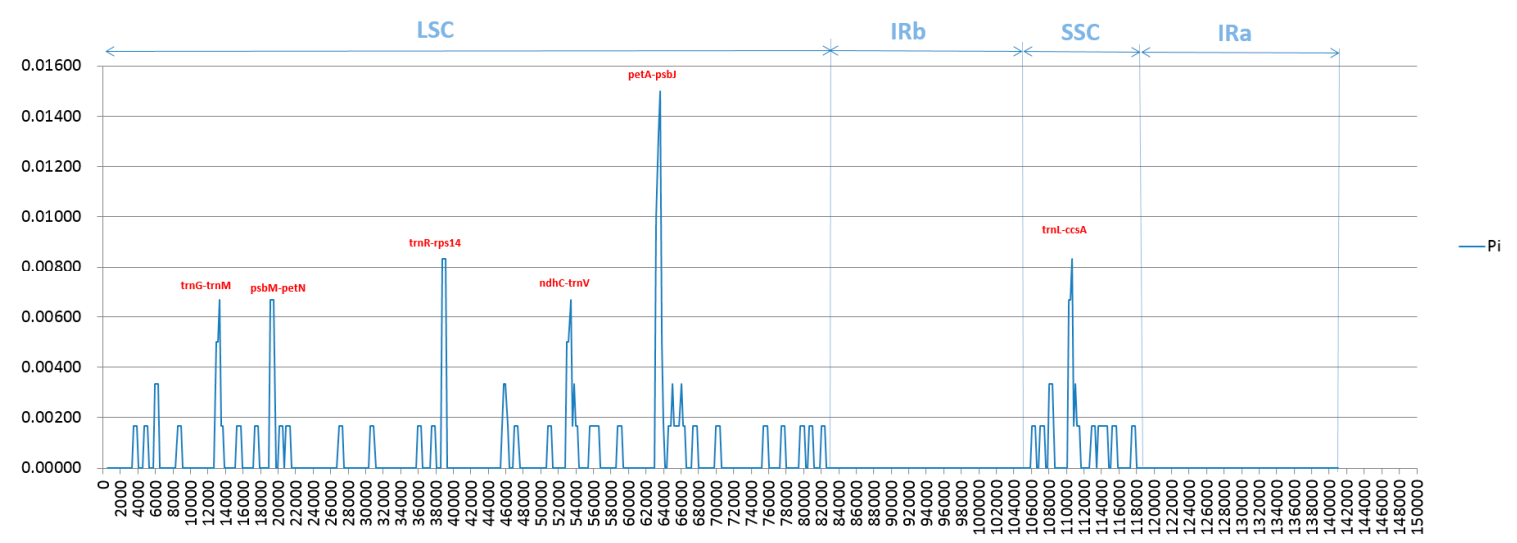

Figure 4. Nucleotide diversity (Pi) based on sliding window analysis in the aligned complete chloroplast genomes of Saccharum officinarum and S. spontaneum. Performing sliding window analysis with: window length $600 \mathrm{bp}$, step size $200 \mathrm{bp}$.

A total of 65 protein genes shared between two sugarcane ancestors were used to estimate average genetic distances. Their distances vary from 0.00000 to 0.00440 , with the average value of 0.00058 (Figure 5). Of these, there are twenty-three genes with greater divergence than average genetic distance 
(0.00058) in the overall. Of which, petD located in the LSC presents the highest level of divergence (0.00440), followed by petB (0.00288) which also located in the LSC, and the top third is $\operatorname{ccs} A(0.00225)$ located in the SSC. Among them, a total of 32 genes showed to be zero referring to genetic distance: 21 in the LSC, each five in the IRa and IRb, and one (ndhE) in the SSC. To estimate the evolution pressure on the specific coding protein gene, we carried out an analysis on nonsynonymous (Ka) and synonymous (Ks) substitution rates, of which synonymous mutation is termed as the mutation of nucleotide without resulting in the corresponding changes of the amino acid sequence, while contrary for the nonsynonymous mutations. In this study, among 65 shared protein genes, the Ka values vary from 0 to 0.0026 , with a total average value of 0.0001 , and the Ks values range from 0 to 0.00345 , with a total average value of 0.00023 . To investigate the selective pressure indicated by the value of $\mathrm{Ka} / \mathrm{Ks}$ on these genes in these two species, the values of $\mathrm{Ka} / \mathrm{Ks}$ were calculated (Figure 5). According to the standards of criteria: neutral $(\mathrm{Ka} / \mathrm{Ks}=1)$, positively selected $(\mathrm{Ka} / \mathrm{Ks}>1)$, and purifying selection $(\mathrm{Ka} / \mathrm{Ks}<1)$, the synonymous mutations are believed to be subjected to the natural selection, while contrary for the nonsynonymous mutations. Abide this rule and compared to $S$. officinarum, the genes of $r p o C 2$ and $r p s 3$ located in the LSC region, together with the genes of $\operatorname{css} A, n d h A$ and $n d h A$ located in the SSC region, were subject to very strong purifying selection in S. spontaneum due to all of their $\mathrm{Ka} / \mathrm{Ks}$ values being zero, while only petB in the LSC region was subject to positive selection. The results indicate that the chloroplast genomes of two sugarcane ancestors have been affected by different environmental pressures during evolution, which may result in the differences in their cp genomes. Genes with $\mathrm{Ka} / \mathrm{Ks}$ values equal to zero include $p s b I$, at $p H$, and $p s a C$, indicating that these genes are under very strong purifying selection.

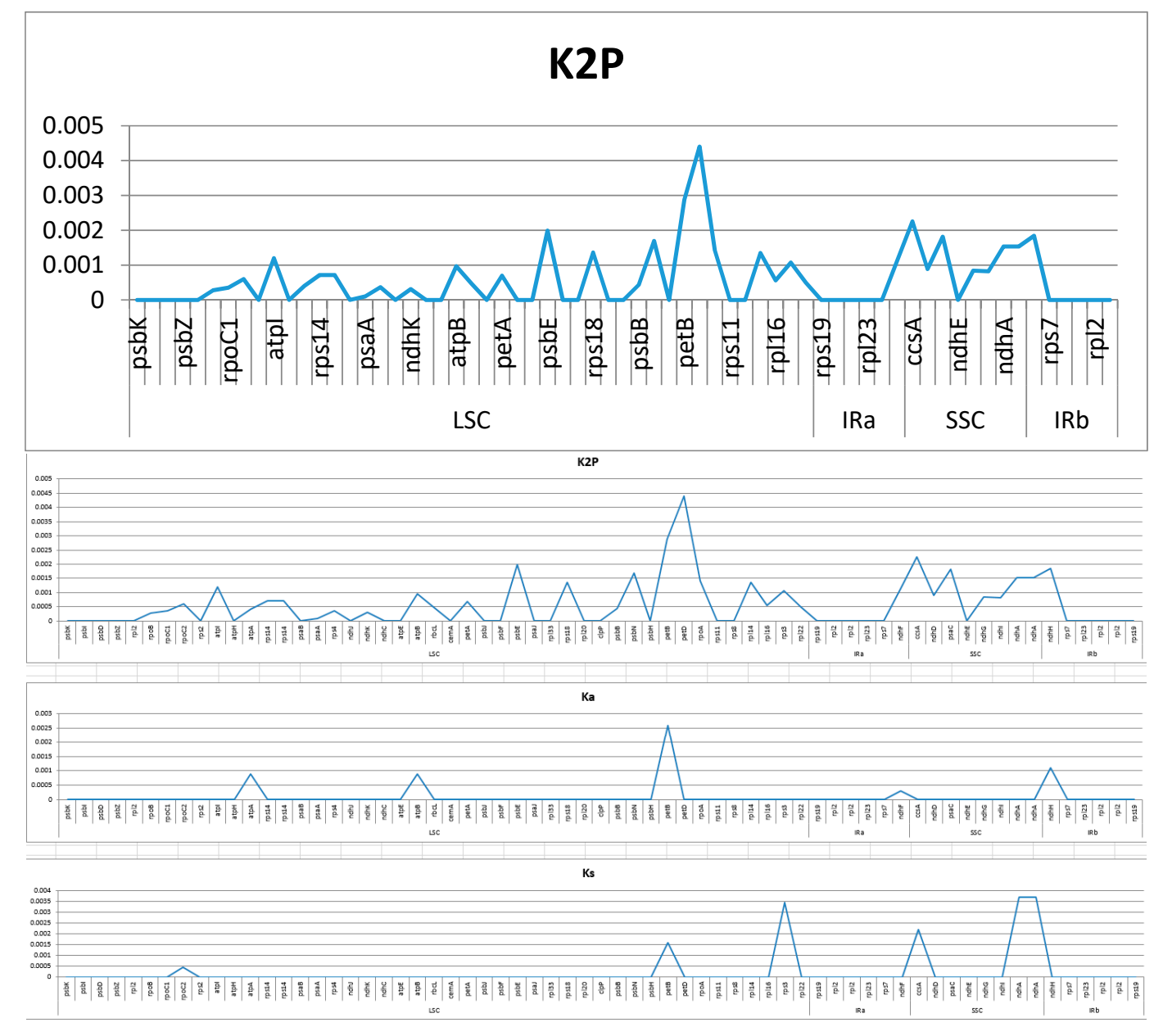

Figure 5. The K2P, Ka and Ks values of the 65 protein-coding genes in high divergent regions from two sugarcane ancestors of Saccharum officinarum and S. spontaneum. 
In order to get the detailed information of base substitutions in CDS genes, single nucleotide polymorphism (SNP) locus identified in chloroplast genomes was carried out. An alignment of the cp genomes indicated that their sequences are highly conserved in two sugarcane ancestors, of which only 24 single nucleotide polymorphic sites identified in 16 genes among all 88 CDS genes in S. spontaneum when compared to $S$. officinarum (Table 2). These genes are $r p o C 1, r p o C 2$, atpA, ycf3, atpB, psbE, rpoA, $r p l 14, r p s 3, n d h B, n d h F, c c s A, n d h D, n d h A, n d h H$ and $n d h B$, of which the gene $n d h B$ has two copies. More than one locus presented in four genes $(\operatorname{atp} B, n d h B, n d h F$ and $\operatorname{ccs} A)$, of which $n d h B$ have two copies, and five SNP sites exist in $\operatorname{ccs} A$. Among the 24 SNP loci, most (16) appeared to be the nonsynonymous substitutions due to the mutation of a single base resulting in the change of amino acids, and only eight SNP loci belong to the synonymous substitutions due to the unchanged of amino acids when base mutation happening. The codons corresponding to the above SNP loci and amino acids in S. officinarum and S. spontaneum were listed in Table 2. They contain 10 transversions (Tvs) and 10 transitions (Ts) which including six Ts between $A$ and $G$, four between $C$ and $T$, and thus giving a ratio of 1:1 for Tv to Ts. Additionally, four codons contain both substitutions, i.e., transversions and transitions.

Table 2. SNP loci identified in Saccharum spontaneum reference to S. officinarum.

\begin{tabular}{|c|c|c|c|c|c|c|}
\hline $\begin{array}{c}\text { Gene Order } \\
\text { in cp } \\
\text { Genome }\end{array}$ & Gene Name & Position & $\begin{array}{c}\text { Code of } \\
\text { Base in } \\
\text { Reference }\end{array}$ & $\begin{array}{l}\text { Code in } \\
\text { S. spontaneum }\end{array}$ & $\begin{array}{c}\text { Code of } \\
\text { Amino Acid } \\
\text { in Reference }\end{array}$ & $\begin{array}{c}\text { Amino } \\
\text { Acids in } \\
\text { S. spontaneum }\end{array}$ \\
\hline 13 & rpoC1 & 2059 & ATA & GTA & I & $\mathrm{V}$ \\
\hline 14 & rpoc2 & 3228 & GGC & GGT & $\mathrm{G}$ & G \\
\hline 19 & $\operatorname{atp} A$ & 572 & GGT & GAT & G & $\mathrm{D}$ \\
\hline 23 & $y c f 3$ & 300 & GCA & GCG & A & A \\
\hline 29 & $\operatorname{atpB}$ & 313 & $\mathrm{ACT}$ & GCT & $\mathrm{T}$ & A \\
\hline 29 & $\operatorname{atpB}$ & 940 & GCC & $\mathrm{ACC}$ & A & $\mathrm{T}$ \\
\hline 38 & $p s b E$ & 57 & TAC & TAT & $\mathrm{Y}$ & $\mathrm{Y}$ \\
\hline 52 & rpoA & 202 & GGG & TGG & G & W \\
\hline 57 & rpl14 & 335 & TTT & TAT & $\mathrm{F}$ & $\mathrm{Y}$ \\
\hline 59 & rps3 & 267 & CCC & CCA & $\mathrm{P}$ & $\mathrm{P}$ \\
\hline 65 & $n d h B$ & 776 & GAC & GGA & $\mathrm{D}$ & G \\
\hline 65 & $n d h B$ & 777 & GAC & GGA & $\mathrm{D}$ & G \\
\hline 70 & $n d h F$ & 868 & ATA & CTA & I & $\mathrm{L}$ \\
\hline 70 & $n d h F$ & 1804 & ATC & CTC & I & $\mathrm{L}$ \\
\hline 72 & $\operatorname{ccs} A$ & 537 & TTT & TTA & $\mathrm{F}$ & $\mathrm{L}$ \\
\hline 72 & $\operatorname{ccs} A$ & 538 & CTT & AGA & $\mathrm{L}$ & $\mathrm{R}$ \\
\hline 72 & $\operatorname{ccs} A$ & 539 & CTT & AGA & $\mathrm{L}$ & $\mathrm{R}$ \\
\hline 72 & $\operatorname{ccs} A$ & 540 & CTT & AGA & $\mathrm{L}$ & $\mathrm{R}$ \\
\hline 72 & $\operatorname{ccs} A$ & 939 & TAT & TAC & Y & $\mathrm{Y}$ \\
\hline 73 & $n d h D$ & 1240 & TTA & GTA & $\mathrm{L}$ & V \\
\hline 78 & $n d h A$ & 858 & TCT & TCC & S & $S$ \\
\hline 79 & $n d h H$ & 793 & ATC & GTC & I & $\mathrm{V}$ \\
\hline 84 & $n d h B$ & 776 & GAC & GGA & $\mathrm{D}$ & G \\
\hline 84 & $n d h B$ & 777 & GAC & GGA & $\mathrm{D}$ & G \\
\hline
\end{tabular}

\subsection{Coding Capacity of Protein Coding Genes (PCGs) and Relative Synonymous Codon Usage (RSCU)}

There is a total of 19,994 codons, which represents the coding capacity of protein coding genes, in cp genome of S. officinarum, and 20,436 codons in S. spontaneum, indicating the stronger coding capacity in the wild species of $S$. spontaneum, while both coding the same number (21) of different types of amino acids. The amino acids, codons and their corresponding numbers, and relative synonymous codon usage (RSCU) were presented in Table 3. Among them, the most abundant amino acid is leucine, with number of 2175 ( $10.88 \%$ of total) and 2228 (10.90\% of total) codons, followed by isoleucine, with number of 1639 and 1671 codons in S. officinarum and S. spontaneum, respectively. The lowest number is cysteine, with only $221(1.105 \%)$ and $224(1.096 \%)$ codons in S. officinarum and S. spontaneum, respectively. In general, the codon preference is similar in both species, while within species, there 
is different preference. The preferred codon is AUG encoding amino acid methionine (Met) with $2.961 \%$ RSCU in both species, followed by UUA encoding leucine with $1.992 \%$ and $1.966 \%$ RSCU in S. officinarum and S. spontaneum, respectively, and GCU, UAU, ACU, UCU, AGA, UUA, GAU, GGA CCU were listed at the third level. On the contrary, the lowest frequency codon is AUA with $0.013 \%$, followed by GUG with $0.026 \%$ in both species. Interestingly, both AUA and GUG encode Met.

Table 3. Coding capacity of protein coding genes (PCGs) and relative synonymous codon usage (RSCU).

\begin{tabular}{|c|c|c|c|c|c|c|}
\hline \multirow{2}{*}{ Amino Acid } & \multirow{2}{*}{ Symbol } & \multirow{2}{*}{ Codon } & \multicolumn{2}{|c|}{ Saccharum officinarum } & \multicolumn{2}{|c|}{ S. spontaneum } \\
\hline & & & Number & RSCU & Number & RSCU \\
\hline * & Ter & UAA & 40 & 1.579 & 39 & 1.520 \\
\hline * & Ter & UAG & 19 & 0.750 & 19 & 0.740 \\
\hline * & Ter & UGA & 17 & 0.671 & 19 & 0.740 \\
\hline $\mathrm{A}$ & Ala & GCA & 368 & 1.198 & 373 & 1.192 \\
\hline $\mathrm{A}$ & Ala & GCC & 189 & 0.615 & 194 & 0.62 \\
\hline $\mathrm{A}$ & Ala & GCG & 134 & 0.436 & 137 & 0.438 \\
\hline $\mathrm{A}$ & Ala & GCU & 538 & 1.751 & 548 & 1.751 \\
\hline $\mathrm{C}$ & Cys & UGC & 55 & 0.498 & 55 & 0.491 \\
\hline $\mathrm{C}$ & Cys & UGU & 166 & 1.502 & 169 & 1.509 \\
\hline $\mathrm{D}$ & Asp & GAC & 155 & 0.437 & 155 & 0.433 \\
\hline $\mathrm{D}$ & Asp & GAU & 555 & 1.563 & 561 & 1.567 \\
\hline $\mathrm{E}$ & Glu & GAA & 794 & 1.497 & 803 & 1.484 \\
\hline $\mathrm{E}$ & Glu & GAG & 267 & 0.503 & 279 & 0.516 \\
\hline $\mathrm{F}$ & Phe & UUC & 403 & 0.718 & 422 & 0.732 \\
\hline $\mathrm{F}$ & Phe & UUU & 720 & 1.282 & 731 & 1.268 \\
\hline G & Gly & GGA & 586 & 1.570 & 596 & 1.567 \\
\hline G & Gly & GGC & 151 & 0.404 & 150 & 0.394 \\
\hline G & Gly & GGG & 275 & 0.737 & 284 & 0.747 \\
\hline G & Gly & GGU & 481 & 1.289 & 491 & 1.291 \\
\hline $\mathrm{H}$ & His & CAC & 120 & 0.512 & 122 & 0.501 \\
\hline $\mathrm{H}$ & His & CAU & 349 & 1.488 & 365 & 1.499 \\
\hline I & Ile & AUA & 522 & 0.956 & 540 & 0.970 \\
\hline I & Ile & AUC & 307 & 0.562 & 308 & 0.553 \\
\hline I & Ile & AUU & 810 & 1.483 & 823 & 1.478 \\
\hline $\mathrm{K}$ & Lys & AAA & 743 & 1.450 & 751 & 1.437 \\
\hline $\mathrm{K}$ & Lys & AAG & 282 & 0.550 & 294 & 0.563 \\
\hline $\mathrm{L}$ & Leu & CUA & 324 & 0.894 & 338 & 0.910 \\
\hline $\mathrm{L}$ & Leu & CUC & 138 & 0.380 & 137 & 0.369 \\
\hline $\mathrm{L}$ & Leu & CUG & 116 & 0.320 & 116 & 0.313 \\
\hline $\mathrm{L}$ & Leu & CUU & 476 & 1.313 & 500 & 1.346 \\
\hline $\mathrm{L}$ & Leu & UUA & 722 & 1.992 & 730 & 1.966 \\
\hline $\mathrm{L}$ & Leu & UUG & 399 & 1.100 & 407 & 1.096 \\
\hline M & Met & AUA & 2 & 0.013 & 2 & 0.013 \\
\hline $\mathrm{M}$ & Met & AUG & 456 & 2.961 & 458 & 2.961 \\
\hline M & Met & GUG & 4 & 0.026 & 4 & 0.026 \\
\hline $\mathrm{N}$ & Asn & $\mathrm{AAC}$ & 208 & 0.515 & 218 & 0.527 \\
\hline $\mathrm{N}$ & Asn & AAU & 599 & 1.485 & 609 & 1.473 \\
\hline $\mathrm{P}$ & Pro & CCA & 216 & 1.013 & 222 & 1.026 \\
\hline $\mathrm{P}$ & Pro & $\mathrm{CCC}$ & 208 & 0.975 & 212 & 0.979 \\
\hline $\mathrm{P}$ & Pro & CCG & 93 & 0.436 & 94 & 0.434 \\
\hline $\mathrm{P}$ & Pro & $\mathrm{CCU}$ & 336 & 1.576 & 338 & 1.561 \\
\hline $\mathrm{Q}$ & Gln & CAA & 524 & 1.555 & 532 & 1.549 \\
\hline$\widehat{Q}$ & Gln & CAG & 150 & 0.445 & 155 & 0.451 \\
\hline $\mathrm{R}$ & Arg & AGA & 361 & 1.758 & 376 & 1.764 \\
\hline $\mathrm{R}$ & Arg & AGG & 110 & 0.536 & 114 & 0.535 \\
\hline $\mathrm{R}$ & Arg & CGA & 273 & 1.330 & 285 & 1.337 \\
\hline
\end{tabular}


Table 3. Cont.

\begin{tabular}{ccccccc}
\hline \multirow{2}{*}{ Amino Acid } & \multirow{2}{*}{ Symbol } & Codon & \multicolumn{2}{c}{ Saccharum officinarum } & \multicolumn{2}{c}{ S. spontaneum } \\
\cline { 3 - 7 } & & & Number & RSCU & Number & RSCU \\
\hline R & Arg & CGC & 106 & 0.516 & 110 & 0.516 \\
R & Arg & CGG & 94 & 0.458 & 100 & 0.469 \\
R & Arg & CGU & 288 & 1.403 & 294 & 1.379 \\
S & Ser & AGC & 104 & 0.434 & 106 & 0.428 \\
S & Ser & AGU & 297 & 1.241 & 303 & 1.225 \\
S & Ser & UCA & 235 & 0.982 & 237 & 0.958 \\
S & Ser & UCC & 286 & 1.195 & 302 & 1.221 \\
S & Ser & UCG & 122 & 0.510 & 130 & 0.526 \\
S & Ser & UCU & 392 & 1.638 & 406 & 1.642 \\
T & Thr & ACA & 300 & 1.109 & 304 & 1.094 \\
T & Thr & ACC & 203 & 0.750 & 211 & 0.759 \\
T & Thr & ACG & 133 & 0.492 & 137 & 0.493 \\
T & Thr & ACU & 446 & 1.649 & 460 & 1.655 \\
V & Val & GUA & 431 & 1.504 & 438 & 1.516 \\
V & Val & GUC & 134 & 0.468 & 137 & 0.474 \\
V & Val & GUG & 150 & 0.524 & 152 & 0.526 \\
V & Val & GUU & 431 & 1.504 & 429 & 1.484 \\
W & Trp & UGG & 347 & 1.000 & 353 & 1.000 \\
Y & Tyr & UAC & 151 & 0.411 & 154 & 0.410 \\
Y & Tyr & UAU & 583 & 1.589 & 598 & 1.590 \\
\hline & & Notes: ${ }^{*}$ stands for the terminator. & & \\
\hline & & & & & &
\end{tabular}

\subsection{Analysis on IR Junctions Proline, Serine, Glutamine, Glycine, Alanine and/or Asparagine}

The IR region is considered to be relatively conserved and exists four boundaries: IRa/LSC, $\mathrm{IRa} / \mathrm{SSC}, \mathrm{IRb} / \mathrm{LSC}$ and IRb/SSC in plant cp genome, while border region contraction and expansion are found to be common and important in the process of evolution, which is the main reason of variation of angiosperm-plant cp genome length $[43,44]$. In current study, the IR boundaries in two sugarcane ancestor species were compared in detail, and presented in Figure 6. There are several genes showed to be contracted at the boundaries, such as: (1) the genes rpl22 and rps19 at the IRb/LSC border contracted $58 \mathrm{bp}$ and $35 \mathrm{bp}$, but located in the LSC and IRb regions, respectively; (2) another rps19 with $36 \mathrm{bp}$ contraction at the IRa/LSC border but located in the IRa region, and $p s b A$ located in LSC region with $90 \mathrm{bp}$ contraction at the IRa/LSC border, together with the gene rps15 at the IRa/SSC border with $153 \mathrm{bp}$ contraction. On the contrary, there also appeared the gene with the characteristic of expansion, such as the gene $n d h F$ at the IRb/SSC border, which located in the SSC region but expanded $29 \mathrm{bp}$ to the IRb region. In addition, the gene $n d h H$ at IRa/SSC border without contraction or expansion. In a word, there are several genes with the characteristics of contraction and expansion, while without differences between S. officinarum and S. spontaneum. Besides, the ycf1 gene, which is traditionally regarded as the hypothetical gene, has been reported to be necessary for plant viability in the Arabidopsis recently [45]. In this study, two species S. officinarum and S. spontaneum are also observed presenting two ycf1 genes in their cp genomes: one contraction at the IRb/SSC boundary and located in the IRb region, another at the IRa/SSC border but located in the IRa region. 


\section{Inverted Repeats}

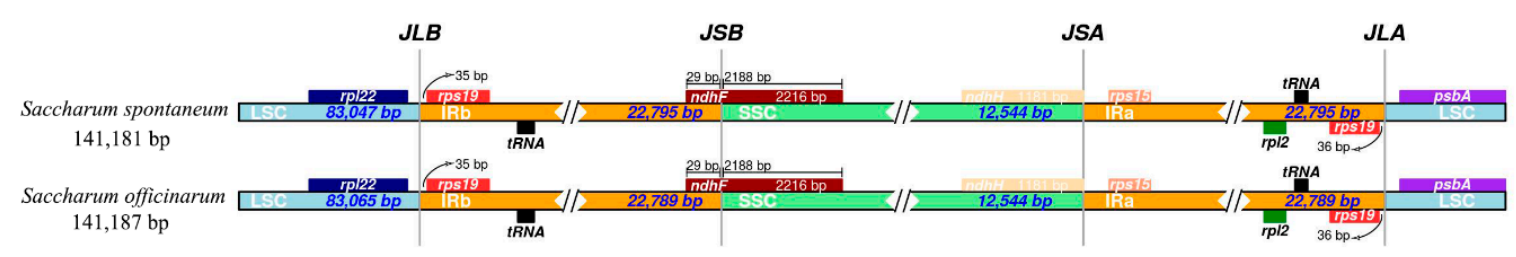

Figure 6. Comparison the junctions of the large single copy (LSC), small single copy (SSC) and inverted repeats (IRs) in chloroplast genomes of Saccharum officinarum and S. spontaneum. Among them, JLB stands for the joint of LSC/ IRb, JSB for the joint of SSC/ IRb, JSA for the jint of SSC/ IRa, and JLA for the joint of LSC/IRa.

\subsection{Repeat Structure Analysis}

When referring to simple sequence repeats (SSRs), different performance parameters can result in different numbers of SSRs detected, strict parameters result in lower amount of SSRs. We performed three different definitions for SSR search, and the results were as follows. When following the stricter performance parameters (unit_size / min_repeats): $1 / 10$ (mononucleotides $\geq 10 \mathrm{nt}$ ), 2/6 (dinucleotides $\geq 6$ repeats), 3/5, 4/5,5/5, and 6/5, only 30 SSRs were identified in the cp genome sequences of S. officinarum, and all are mononucleotides repeats with the longest repeats 14 except one sequence containing two SSR presenting in compound formation '(T)10ctctccta(T) $10^{\prime}$ with 28 bp in size (Table 4). In S. spontaneum, the results showed to be some differences: one more SSRs (32) identified, one sequence containing two SSR, and two presenting in compound formation. These two compound formations are '(A)10ggaactatgattcatactcactatttagacctcgcaaccagactg(A)10' with $65 \mathrm{bp}$ in size, and '(T)10ctctccta(T)10' with $28 \mathrm{bp}$ in length (Table 4). In addition, the T-repeat unit was the most abundant in both species, with number of 20 for $S$. officinarum and 22 for S. spontaneum, respectively. Whilst, the highest frequency of classified repeat types was $\mathrm{A} / \mathrm{T}$ (considering sequence complementary), with the number of 29 and 31 in S. officinarum and S. spontaneum, respectively, which is similar to the previous report [46], while both have only one $G$ repeat.

When according to the parameters used in sugarcane by Melotto-Passarin et al. (2011) but with modifications, only 190 SSRs were identified, and the most abundant repeats were mononucleotide repeats (128), followed by tri- (47), tetra- (9), di- (5) and penta- (1) in S. spontaneum, with only one sequence containing more than one SSR (2) and three SSRs presenting in compound formations: (TATAA)3ttaat(ATA)3, (A)9t(A)8, and (T)10ctctccta(T)10 (supplementary Tables S3 and S5). In S. officinarum, the situations have some differences in spite of being similar in sum: one less SSR (189), the most abundant repeat unit is mononucleotide (126), followed by tri- (47), one sequences containing more than one SSR (2) and three SSRs presenting in compound formation but only one showed to be divergent in size, i.e., (A)9t(A)11 with size $21 \mathrm{bp}$, though the position for most SSRs were different (supplementary Tables S4 and S5). Detailed information about SSR type, SSR sequence, size, start and end positions of the aforementioned SSRs in cp genome is presented in supplementary excel Table S5. Additionally, if a little less strict parameters were performed, i.e., 3rd set of parameters, there were a total of 477 SSRs from S. officinarum were identified, with only one sequences containing more than one SSR and four SSRs presenting in compound formation. While, in S. spontaneum, one less SSRs (476) are identified and five SSRs present in compound formation. According to the above definition, the most abundant repeats were penta-nucleotides, followed by hexa-nucleotides in both species. 
Table 4. SSRs identified in chloroplast genome sequences of Saccharum officinarum and S. spontaneum.

\begin{tabular}{|c|c|c|c|c|c|c|c|}
\hline \multicolumn{4}{|c|}{ S. officinarum } & \multicolumn{4}{|c|}{ S. spontaneum } \\
\hline SSR & Size/bp & $\begin{array}{c}\text { Start } \\
\text { Position }\end{array}$ & $\begin{array}{c}\text { End } \\
\text { Position }\end{array}$ & SSR & Size/bp & $\begin{array}{c}\text { Start } \\
\text { Position }\end{array}$ & $\begin{array}{c}\text { End } \\
\text { Position }\end{array}$ \\
\hline (A)13 & 13 & 3754 & 3766 & (A)15 & 15 & 3753 & 3767 \\
\hline (A)11 & 11 & 4114 & 4124 & (A) 10 & 10 & 4115 & 4124 \\
\hline$(\mathrm{T}) 10$ & 10 & 6446 & 6455 & $(\mathrm{~T}) 11$ & 11 & 6112 & 6122 \\
\hline (A)11 & 11 & 7777 & 7787 & $(\mathrm{~T}) 14$ & 14 & 6446 & 6459 \\
\hline (T)10 & 10 & 9056 & 9065 & (A)11 & 11 & 7781 & 7791 \\
\hline (G)10 & 10 & 11,003 & 11,012 & $(\mathrm{~T}) 10$ & 10 & 9060 & 9069 \\
\hline (T)11 & 11 & 13,372 & 13,382 & $(\mathrm{G}) 10$ & 10 & 11,007 & 11,016 \\
\hline (T)13 & 13 & 16,556 & 16,568 & $(\mathrm{~T}) 11$ & 11 & 13,375 & 13,385 \\
\hline (A)10 & 10 & 18,659 & 18,668 & (A)10 & 10 & 15,948 & 15,957 \\
\hline (A)12 & 12 & 19,205 & 19,216 & $(\mathrm{~T}) 14$ & 14 & 16,554 & 16,567 \\
\hline$(\mathrm{T}) 12$ & 12 & 21,069 & 21,080 & (A)12 & 12 & 19,197 & 19,208 \\
\hline (A) 10 & 10 & 31,914 & 31,923 & $(\mathrm{~T}) 10$ & 10 & 21,061 & 21,070 \\
\hline$(\mathrm{T}) 11$ & 11 & 34,093 & 34,103 & (A)10 & 10 & 31,904 & 31,913 \\
\hline (T)10 & 10 & 34,862 & 34,871 & $(\mathrm{~T}) 11$ & 11 & 34,083 & 34,093 \\
\hline (T)10 & 10 & 35,824 & 35,833 & $(\mathrm{~T}) 10$ & 10 & 34,852 & 34,861 \\
\hline (T)10 & 10 & 38,697 & 38,706 & $(\mathrm{~T}) 10$ & 10 & 35,814 & 35,823 \\
\hline$(\mathrm{T}) 10$ & 10 & 44,257 & 44,266 & $(\mathrm{~T}) 11$ & 11 & 38,687 & 38,697 \\
\hline (T)14 & 14 & 52,367 & 52,380 & $(\mathrm{~T}) 11$ & 11 & 38,836 & 38,846 \\
\hline$(\mathrm{T}) 10$ & 10 & 56,710 & 56,719 & $(\mathrm{~T}) 14$ & 14 & 52,356 & 52,369 \\
\hline (T)10 & 10 & 56,892 & 56,901 & $(\mathrm{~T}) 10$ & 10 & 56,700 & 56,709 \\
\hline (T)10 & 10 & 57,363 & 57,372 & $(\mathrm{~T}) 10$ & 10 & 57,351 & 57,360 \\
\hline (A)11 & 11 & 63,551 & 63,561 & $(\mathrm{~T}) 11$ & 11 & 60,122 & 60,132 \\
\hline (A)11 & 11 & 65,513 & 65,523 & $(\mathrm{~T}) 10$ & 10 & 66,448 & 66,457 \\
\hline$(\mathrm{T}) 10$ & 10 & 67,486 & 67,495 & $(\mathrm{~T}) 10$ & 10 & 67,465 & 67,474 \\
\hline (T)11 & 11 & 68,139 & 68,149 & $(\mathrm{~T}) 12$ & 12 & 68,133 & 68,144 \\
\hline (A)10 & 10 & 73,938 & 73,947 & $\mathrm{C} 2$ & 65 & 73,929 & 73,993 \\
\hline$(\mathrm{T}) 12$ & 12 & 78,482 & 78,493 & $(\mathrm{~T}) 12$ & 12 & 78,474 & 78,485 \\
\hline $\mathrm{C} 1$ & 28 & 79,044 & 79,071 & C3 & 28 & 79,031 & 79,058 \\
\hline (T)14 & 14 & 81,260 & 81,273 & $(\mathrm{~T}) 13$ & 13 & 81,243 & 81,255 \\
\hline$?$ & $?$ & $?$ & $?$ & (A)10 & 10 & 108,278 & 108,287 \\
\hline
\end{tabular}




\subsection{Photosynthetic Ability Analysis}

The chlorophyll relative content (SPAD) and chlorophyll fluorescence parameter Fv/Fm reflect the photosynthesis ability of species. The average SPAD was 29.25 for $S$. officinarum before cold stress, and 28.02 and 27.73 under cold stress for 3 days and 7 days, and 23.37 after removing from incubator to the field for 10 days recovery, while for $S$. spontaneum, the average values were $45.50,41.42,40.42$ and 39.48 , respectively. The significantly higher of SPAD values were found in S. spontaneum than those in S. officinarum, no matter the measurement is performed in control conditions or at the early (3 days) or late time (7 days) under cold stress, and so was after cold stress removing. A significant difference was also observed between two species at recovering stage after stress removing. In addition, unobvious differences were observed between the values measured in early ( 3 days) and late ( 7 days) time under cold stress and during recovery in $S$. spontaneum, though obvious differences were observed between the control conditions and the aforementioned conditions, which indicating its quick response to the environmental stress. However, the situation was different in S. officinarum: unobvious decrease of SPAD value between control conditions and cold stress, while significant decrease during recovery compared to that in the control conditions and in the cold stress, which indicating its slow response to environmental stress and resulting in impaired recovery. These results reflect that the wild species of $S$. spontaneum has stronger photosynthetic capacity than that of $S$. officinarum and is more tolerant to cold stress than that of $S$. officinarum. When referred to chlorophyll fluorescence parameters, the maximal photochemical efficiency in two sugarcane ancestors was estimated (Table 5). The average value of $\mathrm{Fv} / \mathrm{Fm}$, i.e., the ratio of the real-time fluorescence vs. maximum fluorescence, was $0.364 \pm 0.152$ in S. spontaneum, which was significantly higher than that $(0.194 \pm 0.096)$ in S. officinarum after exposure to cold environments for 7 days. In addition, after relieving cold stress and cultured in the control conditions for 10 days, chlorophyll fluorescence could almost not be detected on the treated plants due to the most investigated leaves (5/6) appeared to be zero referring to the Fv/Fm value, which may be caused by excessive low temperature stress and resulted in impaired recovery even if the cold stress having been removed. The situation for this photosynthetic parameter value was similar in both investigated species. However, surprisingly, we found several new tillers appeared in S. spontaneum after for two additional weeks cultured in the control conditions, while no tillers appeared in S. officinarum (Figure S2), suggesting again the stronger tolerance to cold stress and stronger growth compensation ability of S. spontaneum than that of S. officinarum.

Table 5. The values of SPAD and Fv/Fm measured in two sugarcane ancestors of Saccharum.

\begin{tabular}{|c|c|c|c|c|c|}
\hline Investigate Time & \multicolumn{2}{|c|}{ SPAD } & $p$ Value & \multicolumn{2}{|c|}{ Fv/Fm } \\
\hline Before cold stress & $29.25 \pm 1.50 \mathrm{~A}$ & $45.50 \pm 1.40 \mathrm{C}$ & 0.000008 & - & - \\
\hline Culture at $4{ }^{\circ} \mathrm{C}$ for 7 days & $27.73 \pm 1.16 \mathrm{~A}$ & $40.42 \pm 1.25 \mathrm{D}$ & 0.001401 & $0.194 \pm 0.096 \mathrm{~A}$ & $0.364 \pm 0.152 B$ \\
\hline Removing to field for recovery 10 days & $23.37 \pm 2.64 \mathrm{~B}$ & $39.48 \pm 3.34 \mathrm{D}$ & 0.000100 & 0 (5/6 plants) & 0 (5/6 plants) \\
\hline
\end{tabular}

Notes: SPAD, leaf chlorophyll relative content; Fv/Fm (variable chloroplast fluorescence/maximal chloroplast fluorescence) leaf maximum photochemical efficiency. The software SPSS 19.0 was used to perform the test of significance of difference of physiological data SPAD and Fv/Fm under Duncan's significant difference test at the $p<0.05$ level. Different uppercase letters in the same column indicate significant differences at $p<0.01$ level between the different species and different measurement times. All data are presented as the mean $\pm \mathrm{SE}(n=6)$, and $p$ value for $\mathrm{Fv} / \mathrm{Fm}$ is 0.007429 . 


\section{Discussion}

This study provides the new data obtained from two modern sugarcane ancestors $S$. officinarum $(2 \mathrm{n}=80,8 \times)$ and S. spontaneum $(2 \mathrm{n}=80,10 \times)$, and firstly presents the detailed comparison of the complete cp genomes between these two crucial species with the same chromosome number but a little different in ploidy, which may aid to reduce the divergences caused by the number of their chromosomes when referring to the investigation on the expanding function of cold tolerance, as we know that the number of chromosomes varies greatly in S. officinarum and S. spontaneum [24], in spite of the non-existence of chromosomes in chloroplasts. Additionally, S. spontaneum accession Yunnan 83-184 has been widely used in the program of basic hybridization to obtain innovative breeding materials and cross parents due to its strong cold tolerance, vigor and excellent resistance to sugarcane diseases, and Badila, in spite of widely cultivated in China as chewing cane, is one of the several limited original clones of $S$. officinarum. It has been successfully induced to flowering in recent ten years, and used widely in basic hybridization. In addition, this study firstly presents the data associated to the photosynthetic capacity, offers an opportunity to further understand the relations of genes and physiological characters. Besides, the detailed information of sequences of CDS genes can provide the basis for investigation of gene expression in chloroplast under environmental stresses, and SSRs and SNP loci can be used to develop the chloroplast markers to track the genetic background during their utilization in sugarcane breeding. Besides, the polymorphic sites may also be used as the basis for development of the molecular markers associated to interesting phenotypic traits, such as resistance, by detection of the SNP loci among the population derived from the hybridization of S. officinarum and S. spontaneum due to the limited utilization of accessions in two sugarcane ancestor species in modern sugarcane improvement.

Based on the comparison of the cp genomes among six important sugarcane hybrids, including NCo310, SP80-3280, Q155, RB867515, Q165 and RB72454, and two ancestor species S. officinarum (Badila) and S. spontaneum (Yunnan 83-184), highly conserved genome structures were observed, which are similar to other plant species in different genera $[2,3,29,47]$ or in different families $[7,11,27,48,49]$, while the length is divergent among different accessions. Based on the previous reports [6,27-29], GenBank information (Accessions:NC_035224.1; LS975131.1; LN849912.1; LN849914.1; LN896359.1) and two species sequenced in this study, the complete cp genome sequences from 141,151 bp to $141,348 \mathrm{bp}$ among these 11 accessions including the above six sugarcane hybrids and five sugarcane ancestor accessions (Table 6). The length for SSC region is exactly the same except SP80-3280 with additional two base-pairs, which was sequenced in early time [28]. However, diversification mainly appears in the length of LSC, from $83,017 \mathrm{bp}$ to $83,226 \mathrm{bp}$. The maximum difference in length existed in the species $S$. spontaneum (from 83,047 to 83,226 bp), which may come from much diversification in ploidy $(2 n=4 \times$ to $12 \times)$ and in the number of chromosomes $(2 n=40-128)$, in spite of chloroplast without containing the chromosome, followed by another ancestor S. officinarum, with $83,065 \mathrm{bp}$ for Badila and $83,042 \mathrm{bp}$ for IJ76-514. Merely, most modern sugarcane varieties share the same length in the LSC region except for RB72454 with 30 reduced base pairs. 
Table 6. The structure and length of the chloroplast genome sequences in sugarcane hybrids and their ancestors Saccharum officinarum and S. spontaneum.

\begin{tabular}{|c|c|c|c|c|c|c|c|c|c|c|c|}
\hline \multirow{2}{*}{$\begin{array}{c}\text { Species } \\
\text { Accession }\end{array}$} & \multicolumn{2}{|c|}{ S. officinarum } & \multicolumn{3}{|c|}{ S. spontaneum } & \multicolumn{6}{|c|}{ S. officinarum Hybrids } \\
\hline & Badila & IJ76-514 & $\begin{array}{l}\text { Yunnan } \\
\text { 83-184 }\end{array}$ & IJ76-287 & SES234B & RB867515 & Q155 & SP80-3280 & NCo310 & RB72454 & Q165 \\
\hline Length/bp & 141,187 & 141,176 & 141,181 & 141,348 & 141,185 & 141,181 & 141,181 & 141,182 & 141,182 & 141,151 & 141,181 \\
\hline $\mathrm{LSC} / \mathrm{bp}$ & 83,065 & 83,042 & 83,047 & 83,226 & 83,063 & 83,047 & 83,047 & 83,048 & 83,048 & 83,017 & 83,047 \\
\hline $\mathrm{SSC} / \mathrm{bp}$ & 12,544 & 12,544 & 12,544 & 12,544 & 12,544 & 12,544 & 12,544 & 12,546 & 12,544 & 12,544 & 12,544 \\
\hline $\mathrm{IRa} / \mathrm{bp}$ & 22,789 & 22,795 & 22,795 & 22,789 & 22,789 & 22,795 & 22,795 & 22,794 & 22,795 & 22,795 & 22,795 \\
\hline $\mathrm{IRb} / \mathrm{bp}$ & 22,789 & 22,795 & 22,795 & 22,789 & 22,789 & 22,795 & 22,795 & 22,794 & 22,795 & 22,795 & 22,795 \\
\hline $\begin{array}{l}\text { Accession } \\
\text { numbers in } \\
\text { NCBI }\end{array}$ & $\begin{array}{l}\text { Obtained } \\
\text { in this } \\
\text { study }\end{array}$ & NC_035224.1 & $\begin{array}{l}\text { Obtained } \\
\text { in this } \\
\text { study }\end{array}$ & LS975131.1 & LN849912.1 & KX507245.1 & NC_029221.1 & NC_005878.2 & NC_006084.1 & LN849914.1 & LN896359.1 \\
\hline
\end{tabular}


In addition to the divergences in length, differences are also present in gene content of $\mathrm{cp}$ genome. There are 38 tRNA genes presented in cp genomes of Badila and Yunnan 83-184, while there is 39 in RB867515 [29], and certainly differing more from the early report of sugarcane cp genome, such as 116 identified genes including 82 CDS, four rRNA and 30 tRNA genes in sugarcane hybrid SP80-3280 [28], which may be due to the difference in sequencing technique. Additionally, the number of the identified genes and duplicated genes in the cp genomes were divergent more in different genera and families. Additionally, as if it is not always appeared to have a positive relation between the size of cp genome and the gene number, in spite of most of them do. In this study, two sugarcane ancestors in genus Saccharum have 134 genes identified with 141,187 bp or 141,181 bp in size, and 20 duplicated genes, while Triticum turgidum subsp. Durum belongs to the same family (Gramineae), which has 135 genes with a shorter length $(135,948 \mathrm{bp})$ [15] than those in sugarcane clones. This phenomenon is also observed between T. timopheevii cultivar TA944 (KJ614409) with 136,124 bp in size while only 85 annotated genes, and T. timopheevii cultivar Tim01 (NC_024764) with 136,157 bp in size with 125 annotated genes [15]. Different situation was found between Hordeum vulgare and sugarcane, and Sorghum bicolor and sugarcane, both groups have the characteristics of less annotated genes (131) with the smaller length $(136,462 \mathrm{bp}$ and 140,754 bp) [50], and thus suggesting a positive relation between the length of $\mathrm{cp}$ genome and the gene number. A similar situation was also found in Ipomoea $\mathrm{L}$. from Convolvulaceae [51] and between Triticum turgidum subsp. Durum (KM352501) and T. urartu (NC_021762) [15].

More divergences were observed when referred to the base substitution events. In this study, we find 24 SNP loci in S. spontaneum when reference to S. officinarum, which was different from the findings of Vidigal et al. [29], in which sugarcane hybrid RB867515 was identical to Q155, and only four SNPs and one Indel differing from NCo310, six SNPs and two Indels differing from SP80-3280. Even though this rate of base substitutions $(0.017 \%)$ between S. spontaneum and S. officinarum is low at the intrageneric level, but higher than that observed by Vidigal et al. [29]. This rate was much lower than the 5940, 6260 and 5992 between Fagopyrum luojishanense and each of F. dibotrys, F. esculentum and F. tataricum [46], and the 591 (0.38\%) between Solanum bulbocastanum and S. tuberosum [48], and the 235 $(0.15 \%)$ between Mikania micrantha and M. cordata [7] and the 231 (0.15\%) between Machilus balansae and M. yunnanensis [47]. Specifically, the SNPs existed in 72 out of 79 CDS genes among seven Panax species [52], with the exception of seven genes: $p s a$ ], $p s b N, r p l 23, p s b F, p s b L, r p s 18$, and $r p s 7$. In addition, when referring to SNP density, lower density in IR regions was observed than those in LSC and SSC regions, similar phenomena were observed in the other species, such as in Panax [52], Solanum [48], and Machilus [47], implying that it is a common phenomenon. Among the 24 SNP loci, most (16) appeared to be the nonsynonymous substitutions, and this rate $(66.67 \%)$ of the nonsynonymous and synonymous substitutions is high. Whilst, the ratio of 1:1 for Tv to Ts between S. spontaneum and S. officinarum suggests that substitutions occur with unbias, while substitutions occurring with a bias and in favor of transversions was observed between $M$. micrantha and $M$. cordata with the rate of 1:0.74 [7]. The base substitutions identified in the current study may help to understand the phylogeny and population genetics of Saccharum, and recognize the real hybrids in sugarcane genetic improvement.

Codons play an important role in the process of transmission of genetic information. The number of total codons for protein coding genes are divergent in different species. There are only 19,994 codons in S. officinarum var. Badila and 20,436 in S. spontaneum Yunnan 83-184, less than those in M. micrantha $(26,417)$ and M. cordata $(26,414)$ [7], while coding more CDS genes $(88)$ than that $(80)$ in M. micrantha and M. cordata, implying the stronger coding capacity. However, the most and the least abundant amino acids are the same in two sugarcane ancestors in Gramineae. They are leucine and cysteine, respectively, and the usage frequency is also high similarity. This high similarity is also observed between different families, such as in Mikania (Asteraceae), the most abundant is leucine $(10.7 \%)$ and the least abundant is cysteine (1.12\% and $1.13 \%$ ) [7] compared to $10.88 \%$ and $10.90 \%$ for leucine, and $1.105 \%$ and $1.096 \%$ for cysteine in S. officinarum and S. spontaneum, respectively, in the current study. This situation is similar in the same family but different genus, such as M. floridulus (accession: 
LN869215.1) in Gramineae [30]. In addition, a codon use preference is common in plant species. In this study, obvious codon use preferences were observed in two sugarcane ancestors S. officinarum and S. spontaneum, and the most preferred codon is AUG, followed by UUA, and then GCU, UAU, ACU, UCU, AGA, UUA, GAU, GGA and CCU with the similar preferences in both species. Similar opinion of obvious codon use preferences was also found in the previous studies of Pyrus [53] and F. dibotrys [44]. However, the preferred codons are divergent in different species. For example, the most preferred codon is AUG in our study, while the frequently used codons are ATT, AAA, GAA, AAT and TTT in Pyrus, and the most preferred one is ATT [53], indicating that different species have divergent codon preferences, which is formed during the long-term of evolutionary process.

Repeat structures are correlated with rearrangement and recombination of plastome including chloroplast genome. SSRs in cp genome are potentially useful markers for population genetics due to a high variation commonly appeared within the same species [54]. In our study, a large number of repeats were detected in the cp genomes of sugarcane ancestors, and most repeats were located in intergenic regions, which is similar to the species in Fagopyrum [44], and most are perfect types with only one to two compound SSRs in either of the three sets of parameters performed in this study, which is similar to the species M. micrantha and M. cordata [7]. However, performance parameters for searching SSRs determine the number of SSRs detected, and significant difference will be observed after carrying out three sets of parameters. There are 30 limited SSRs with mononucleotide repeats when parameters of $1 / 10$ (mononucleotides $\geq 10 \mathrm{nt}$ ), $2 / 6$ (dinucleotides $\geq 6$ repeats), $3 / 5,4 / 5,5 / 5$, and (6/5) were performed, compared to a large number of more than 470 SSRs when less strict parameters were performed. Thus, performance parameter is the most important factor in investigation of SSR, which can be adjusted according to the desired and objective.

In addition to the crucial function of performing photosynthesis in the chloroplast, it also evolves to extend functions, such as tolerance to environmental stresses of low temperature. In chloroplast, impaired chlorophyll biosynthesis was observed when plants exposed to cold stress, which is attributed to down-regulation of gene expression, protein abundance and enzyme activities [32,55-57]. The reduced photosynthesis, caused by low temperature stress, is due to decline in Fv/Fm, PSII, inhibition of electron transport, and consequent declined photophosphorylation and $\mathrm{CO}_{2}$ assimilation [58-63]. In the current study, compared to $S$. officinarum, the values of SPAD in S. spontaneum were always significantly higher no matter they are cultivated in control temperature, exposed to low temperature or during recovery, and so is for $\mathrm{Fv} / \mathrm{Fm}$ when exposure to low temperature. In addition, during recovery, there are several new strong tillers observed in S. spontaneum but no tillers appeared in S. officinarum, indicating a strong growth compensation ability in S. spontaneum, in spite of the value of $\mathrm{Fv} / \mathrm{Fm}$ can not be detected in both species, which may result from excessive low temperature stress. However, when compared with the Fv/Fm values obtained in sugarcane under control field conditions, these values observed in both accessions of Badila and Yunnan 83-184 are quite low [64]. For Badila, the Fv/Fm value observed in cold stress in this study is only $27 \%$ of its value in control field conditions [64]. It suggests that S. spontaneum Yunnan 83-184 exhibits the stronger tolerance to cold stress than S. officinarum Badila, and the expanding function to low temperature stress in chloroplast also observed in sugarcane. In addition, the stronger tolerance to low temperature environmental stress of $S$. spontaneum can also reflect in quick response to cold stress than that in S. officinarum, and thus results in less damage. Merely, low temperature still has a serious impact on chloroplast of S. spontaneum and S. officinarum, which results in obvious decrease of the Fv/Fm value but unobvious for SPAD during cold stress. 


\section{Materials and Methods}

\subsection{Plant Material, Sample Collection and DNA Preparation}

Considering the complexity and diversity of ploidy and chromosome number of Saccharum officinarum and S. spontaneum, accessions from these two sugarcane ancestor species, used for analysis of chloroplast genome sequence, especially cold tolerance, should have the same or at least not much difference in ploidy and chromosome number, because both factors have great influence on phenotypes, including biomass. Thus, two accessions Badila and Yunnan 83-184 from the aforementioned ancestor species were selected for investigation. Young fresh leaves of Saccharum officinarum var. Badila (chromosome number $2 n=80$, ploidy $8 \times)$ and $S$. spontaneum Yunnan 83-184 $(2 n=80,10 \times)$ were collected from the National Sugarcane Germplasm Resource Garden in Kaiyuan, Yunnan, China. Yunan 83-184 is an important wild type of $S$. spontaneum, which has good performance in drought, cold and salty stress resistance, and growth vigor, and has been widely used in germplasm innovation. Badila is one of the several limited original accessions of S. officinarum, which is also popularly used as the cultivar for chewing cane in China for a long time. A modified cetyl-trimethylammonium bromide (CTAB)-based method [65] was used for extracting leaf total DNA. Then, the purified DNA with suitable quality was stored at $-80^{\circ} \mathrm{C}$ for further use.

\subsection{DNA Sequencing and Genome Assembly}

The purified DNA was used for the construction of chloroplast DNA libraries. Illumina HiSeq 2500 was used to generate raw sequence reads for this project. Since the DNA sample for sequencing are a mixture from nucleus and organelles, the cpDNA sequences needed to be separated from the original raw reads. After removing adaptors and low-quality reads $(\mathrm{Q} \leq 30)$, clean reads were assembled by Genome Assembler SPAdes (version 3.13.1) (cab.spbu.ru/software/spades/v) to get the seed sequences, then kmer $(\mathrm{kmer}=$ " $55,87,121$ ") iterative extend seed, and then using SSPACE to scaffold contigs. The software GapFiller v2.1.1 (https://jaist.dl.sourceforge.net/project/gapfiller/v2.1.1/gapfiller-2.1.1.tar.gz) was used for filling up the gaps. Before assembling, chloroplast DNA (cpDNA) sequences were drawn by the method of Bowtie2 version 2.2.4 by Ben Langmead (langmea@cs.jhu.edu, www.cs.jhu.edu/ \{\}langmea) from the paired-end reads by comparing to the known database of plant chloroplast genomes constructed by the Genepeer Biotechnology Company (Nanjing, China), in which the cp genome sequences were downloaded from NCBI, and then these reads were used to assemble the cp genomes. Assembled contigs were subjected to BLAST against the existing complete cp sequence of $S$. spontaneum IJ76-287 (accession number: LS975131.1), which was also used as the reference cp genome to assemble into the complete circular cp genome sequence. The following method was occupied for filling up the gaps between contigs, and described as: using BLAST to map the raw reads onto both ends of the assembled contigs (step one), and then scaffolds and joining overlapping reads to elongate the contig (step two). The above two steps were repeatedly carried out till all the gaps between contigs were filled up. Sequence assembly of clean reads was carried out according to the chloroplast genome sequences of reference species. Gene annotation, RSCU analysis, cpSSR analysis, statistical analysis of K2P, Ka and Ks, and co-linear analysis of two sequenced species were conducted based on the assembly results of cp sequences.

\subsection{Comparison of Complete cp Genomes, Genomic Annotation and Analysis}

BioEdit v7.2.5 (https://download.informer.com/win-1191694432-75407f8f-6a559e4d/bioedit.zip) was occupied to investigate variations in the $\mathrm{cp}$ genome of S. officinarum and S. spontaneum. The LSC/IRB/SSC/IRA boundary regions were compared by BLASTN of homologous sequences. The software of BioEdit v7.2.5 was used to extract the sequences of coding, rRNA, tRNA, intronic and intergenic sequences, and the same for analysis of GC content. Prodigal Software v2.6.3 (https://github.com/hyattpd/Prodigal) and Software Maker v2.31.10 (http://www.yandell-lab.org/ software/maker.html) were used for gene prediction, and the online tool DOGMA was used to 
assist verification. Additionally, an investigation of synonymous codon usage was accomplished by CodonW v1.4.2. DOGMA (http://dogma.ccbb.utexas.edu/ http://dogma.ccbb.utexas.edu, the Dual Organellar GenoMe Annotator), while start codons, stop codons, intron and exon positions were manually adjusted by means of comparison with homologous genes from $S$. spontaneum $\mathrm{cp}$ genomes (LS975131.1). ORF Finder (http://www.ncbi.nlm.nih.gov/gorf/orfig.cgi) was used to determine the open reading frames (ORF). The software Aragorn was used to predict tRNA, and Hmmer for rRNA genes [66]. OGDraw (http://ogdraw.mpimp-golm.mpg.de/) was used to generate the circular genome map, and the sequences of complete cp genome were deposited in GenBank. In addition, the alignment between the chloroplast genomes of S. officinarum and S. spontaneum was obtained by Clustalw v2.1 (http://www.clustal.org/download/current/clustalw-2.1.tar.gz). Using software DnaSP v5.0 (http://www.ub.edu/dnasp/). to perform an analysis of sliding window by searching of nucleotide diversity (Pi) with the standards: 600-bp window length and 200-bp step size. Clustalw v2.1 was used for multiple sequence alignment, and sequence divergences of pair-wise were estimated by Kimura's two-parameter model [67]. KaKs_Calculator2.0 (https://sourceforge.net/projects/kakscalculator2/) [68] was used for estimating Ka and Ks. Besides, BLASTN was used to investigate the boundary regions.

\subsection{Repeat Structure Analysis}

In the cp genomes of $S$. officinarum and S. spontaneum, microsatellites or simple sequence repeats (SSRs) among tandem repeat structures were identified by MISA (MIcroSAtellite identification tool) (http://pgrc.ipk-gatersleben.de/misa/). In order to compare the differences, we performed SSR identification following three different definitions (unit_size/ minimum number of repeats), which as follows: (1) 1st set of parameters: including at least ten for mononucleotides (1/10), six repeat units for dinucleotides (2/6), five for tri-(3/5), tetra-(4/5), penta-(5/5), and hexa-nucleotides (6/5); (2) 2nd set of parameters based on the report of Melotto-Passarin et al. [69] but with modification, and the definition of microsatellites (unit size/minimum number of repeats): (1/8) (2/5) (3/3) (4/3) (5/3) (6/3); 3rd set of performance parameters, similar to Raubeson et al. [43], with 10, or more than 10, nucleotides belonging to a less strict parameters for tetra-, penta-, and hexa- nucleotide repeat units: $(1 / 10),(2 / 5)$, $(3 / 4),(4 / 3),(5 / 2)$, and $(6 / 2)$.

\subsection{Photosynthetic Parameter Measurement and Statistical Analysis}

Stalks of S. officinarum and S. spontaneum accessions with single bud were cultivated in pots with $50 \mathrm{~cm}$ (diameter) $\times 50 \mathrm{~cm}$ (high). Six-month-old plants with seven full-expanded leaves were used to investigate the chlorophyll content, chlorophyll fluorescence parameters and the effects of cold stress on these two parameters. Six biological replicates were set, and one pot for one replicate containing two plants. The middle part of the +1 leaf on one plantlet from each pot was used for measurement. Cold stress was carried out in the low temperature light incubator (LGX-1200D-LED, PRANDT Instrument Co., Ltd., Hangzhou, China) under $4{ }^{\circ} \mathrm{C}$ with $12 \mathrm{~h}$ light/ $12 \mathrm{~h}$ darkness, and light intensity is same (25,000 Lux), and stopped after 7 days, followed by removing pots to field. A SPAD-502 Plus (Konica Minolta Sensing, Inc., Osaka, Japan) was used to measure the chlorophyll relative content on six plants reference to the previous report [70]. A system of IMAGING-PAM fluorometer (Walz, Effeltrich, Germany) was used to measure the chlorophyll fluorescence parameters on the same six plants and the same leaves, which previously used to investigate the SPAD values according to the method described by $\mathrm{Su}$ et al. [71], following a dark adaptation for $2 \mathrm{~h}$. The measurement of chlorophyll relative content was performed before cold stress, culturing for 3 days and 7 days under low temperature, and at 10 days after removing to field for recovering growth. Additionally, the software SPSS 19.0 system (SPSS IBM, Somers, NY, USA) was used to perform the test of significance of difference of physiological data SPAD and Fv/Fm under Duncan's significant difference test at the $p<0.05$ level.5. Conclusion 
The length of complete cp genome containing a quadripartite structure is $141,187 \mathrm{bp}$ for S. officinarum, which is only six bp larger than that of S. spontaneum. Its LSC and IR are, respectively, $18 \mathrm{bp}$ larger and $6 \mathrm{bp}$ shorter than those of $S$. spontaneum, while GC contents are same (38.44\%). They have the same number of the annotated genes, duplicated genes, and introns (without counting a trans-splicing gene rps12), which indicated the high conservativeness in their cp genome sequences. However, each species has its unique genes, and most (16/24) of the detected SNPs are nonsynonymous substitutions in S. spontaneum referenced to $S$. officinarum, of which $\operatorname{ccs} A$ has four SNP loci. In addition, a ratio of 1:1 for $\operatorname{Tv}(10)$ to $T s$ (10) was observed, and four codons contain both substitutions. IR junction analysis indicates that both two ancestors have the same number (5) of contraction genes, and only $n d h F$ at the IRb/SSC border with characteristic of expansion. There are more codons for coding amino acids in S. spontaneum than that in S. officinarum, and there is different preference within species, while both have obvious codon preference and the codons with highest- and lowest-frequency are the same, and so are the most abundant and least amino acids. A batch of SSRs with different repeat types were identified, which could be used to infer the population genetic structure. The wild species S. spontaneum exhibits much stronger photosynthetic ability and cold tolerance, which are reflected by the significant higher SPAD in control conditions, under cold stress and during recovery than those in S. officinarum, together with the obvious higher chlorophyll fluorescence parameters Fv/Fm when exposed to low temperature, which can also be indicated by new tillers and implied by quick response to low temperature environments. This study adds our new knowledge of the two sugarcane ancestors and highlights the differences in the cp genomes, photosynthetic ability and cold tolerance between two important species, and provides the clues to promote genetic improvement of photosynthetic ability and cold resistance in sugarcane.

Supplementary Materials: Supplementary materials can be found at http://www.mdpi.com/1422-0067/20/15/ 3828/s1.

Author Contributions: L.X., F.L. and F.X. conceived and designed the experiments, F.X. and L.X. prepared the materials. L.X., L.H., S.G. and L.X. performed the experiments and conducted data analysis; F.X. wrote the manuscript. L.X., F.L., Y.S. and F.X. revised the manuscript. All of the authors read and approved the final version of the manuscript.

Funding: This research was funded by the Sugar Crop Research System of China (CARS-17) and National Natural Science Foundation of China (Grant No. 31560417).

Conflicts of Interest: The authors declare no conflict of interest.

\section{References}

1. Jansen, R.K.; Raubeson, L.A.; Boore, J.L.; Depamphilis, C.W.; Chumley, T.W.; Haberle, R.C.; Wyman, S.K.; Alverson, A.; Peery, R.; Herman, S.J;; et al. Methods for obtaining and analyzing whole chloroplast genome sequences. Methods Enzymol. 2005, 395, 348-384. [PubMed]

2. Curci, P.L.; De Paola, D.; Danzi, D.; Vendramin, G.G.; Sonnante, G. Complete chloroplast genome of the multifunctional crop globe artichoke and comparison with other asteraceae. PLoS ONE 2015, 10, e0120589. [CrossRef] [PubMed]

3. Li, X.; Li, Y.F.; Zang, M.Y.; Li, M.Z.; Fang, Y.M. Complete chloroplast genome sequence and phylogenetic analysis of Quercus acutissima. Int. J. Mol. Sci. 2018, 19, 2443. [CrossRef] [PubMed]

4. Palmer, J.D. Comparative organization of chloroplast genomes. Annu. Rev. Genet. 1985, 19, 325-354. [CrossRef] [PubMed]

5. Xu, D.H.; Abe, J.; Sakai, M.; Kanazawa, A.; Shimamoto, Y. Sequence variation of non-coding regions of chloroplast DNA of soybean and related wild species and its implications for the evolution of different chloroplast haplotypes. Theor. Appl. Genet. 2000, 101, 724-732. [CrossRef]

6. Hoang, N.V.; Furtado, A.; McQualter, R.B.; Henry, R.J. Next generation sequencing of total DNA from sugarcane provides no evidence for chloroplast heteroplasmy. New Negat. Plant Sci. 2015, 1,33-45. [CrossRef] 
7. Su, Y.; Huang, L.; Wang, Z.; Wang, T. Comparative chloroplast genomics between the invasive weed Mikania micrantha and its indigenous congener Mikania cordata: Structure variation, identification of highly divergent regions, divergence time estimation, and phylogenetic analysis. Mol. Phylogenet. Evol. 2018, 126, 181-195. [CrossRef]

8. Wolfe, K.H.; Li, W.H.; Sharp, P.M. Rates of nucleotide substitution vary greatly among plant mitochondrial, chloroplast, and nuclear DNAs. Proc. Natl. Acad. Sci. USA 1987, 84, 9054-9058. [CrossRef]

9. Ingvarsson, P.K.; Ribstein, S.; Taylor, D.R. Molecular evolution of insertions and deletion in the chloroplast genome of Silene. Mol. Biol. Evol. 2003, 20, 1737-1740. [CrossRef]

10. Martin, G.E.; Rousseau-Gueutin, M.; Cordonnier, S.; Lima, O.; Michon-Coudouel, S.; Naquin, D.; De Carvalho, J.F.; Ainouche, A.; Salmon, A.; Ainouche, A. The first complete chloroplast genome of the genistoid legume Lupinus Luteus: Evidence for a novel major lineage-specific rearrangement and new insights regarding plastome evolution in the legume family. Ann. Bot. 2014, 113, 1197-1210. [CrossRef]

11. Zhang, Y.Z.; Ma, J.; Yang, B.X.; Li, R.Y.; Zhu, W.; Sun, L.L.; Tian, J.K.; Zhang, L. The complete chloroplast genome sequence of Taxus chinensis var. mairei (Taxaceae): Loss of an inverted repeat region and comparative analysis with related species. Gene 2014, 540, 201-209. [CrossRef]

12. Group, C.P.W.; Hollingsworth, P.M.; Forrest, L.L.; Spouge, J.L.; Hajibabaei, M.; Ratnasingham, S.; Fazekas, A.J. A DNA barcode for land plants. Proc. Natl. Acad. Sci. USA 2009, 106, 12794-12797. [CrossRef]

13. Atherton, R.A.; McComish, B.J.; Shepherd, L.D.; Berry, L.A.; Albert, N.W.; Lockhart, P.J. Whole genome sequencing of enriched chloroplast DNA using the Illumina GAII platform. Plant Methods 2010, 6, 22. [CrossRef]

14. Doorduin, L.; Gravendeel, B.; Lammers, Y.; Ariyurek, Y.; Chin-A-Woeng, T.; Vrieling, K. The complete chloroplast genome of 17 individuals of pest species Jacobaea vulgaris: SNPs, microsatellites and barcoding markers for population and phylogenetic studies. DNA Res. 2011, 18, 93-105. [CrossRef]

15. Awad, M.; Fahmy, R.M.; Mosa, K.A.; Helmy, M.; El-Feky, F.A. Identification of effective DNA barcodes for Triticum plants through chloroplast genome-wide analysis. Comput. Biol. Chem. 2017, 71, 20-31. [CrossRef]

16. Chen, X.L.; Zhou, J.G.; Cui, Y.X.; Wang, Y.; Duan, B.Z.; Yao, H. Identification of Ligularia herbs using the complete chloroplast genome as a super-barcode. Front. Pharmacol. 2018, 9, 695. [CrossRef]

17. Yousefzadeh, H.; Khodadost, A.; Abdollahi, H.; Ali, S.S.; Kozlowski, G.; Bina, H. Biogeography and phylogenetic relationships of Hyrcanian wild apple using cpDNA and ITS noncoding sequences. Syst. Biodivers. 2019. [CrossRef]

18. Niu, Y.T.; Jabbour, F.; Barrett, R.L.; Ye, J.F.; Zhang, Z.Z.; Lu, K.Q.; Lu, L.M.; Chen, Z.D. Combining complete chloroplast genome sequences with target loci data and morphology to resolve species limits in Triplostegia (Caprifoliaceae). Mol. Phylogenet. Evol. 2018, 129, 15-26. [CrossRef]

19. D'Hont, A.; Paulet, F.; Glaszmann, J.C. Oligoclonal interspecific origin of 'North Indian' and 'Chinese' sugarcanes. Chromosome Res. 2002, 10, 253-262. [CrossRef]

20. Zhang, J.S.; Zhang, Q.; Li, L.T.; Tang, H.B.; Zhang, Q.; Chen, Y.; Arrow, J.; Zhang, X.T.; Wang, A.Q.; Miao, C.Y.; et al. Recent polyploidization events in three Saccharum founding species. Plant Biotechnol. J. 2018, 17, $264-274$. [CrossRef]

21. D'Hont, A. Unraveling the genome structure of polyploids using FISH and GISH; examples of sugarcane and banana. Cytogenet. Genome Res. 2005, 109, 27-33. [CrossRef]

22. Zhang, J.S.; Zhang, X.T.; Tang, H.B.; Zhang, Q.; Hua, X.T.; Ma, X.K.; Zhu, F.; Jones, T.; Zhu, X.G.; Bowers, J.; et al. Allele-defined genome of the autopolyploid sugarcane Saccharum spontaneum L. Nat. Genet. 2018, 50, 1565-1573. [CrossRef]

23. Garsmeur, O.; Droc, G.; Rudie, A.; Grimwood, J.; Potier, B.; Aitken, K.S.; Jenkins, J.; Martin, G.; Charron, C.; Hervouet, C.; et al. A mosaic monoploid reference sequence for the highly complex genome of sugarcane. Nat. Commun. 2018, 9, 2638. [CrossRef]

24. Irvine, J.E. Saccharum species as horticultural classes. Theor. Appl. Genet. 1999, 98, 186-194. [CrossRef]

25. D’Hont, A.; Ison, D.; Alix, K.; Roux, C.; Glaszmann, J.C. Determination of basic chromosome numbers in the genus Saccharum by physical mapping of ribosomal RNA genes. Genome 1998, 41, 221-225. [CrossRef]

26. Ha, S.; Moore, P.H.; Heinz, D.; Kato, S.; Ohmido, N.; Fukui, K. Quantitative chromosome map of the polyploid Saccharum spontaneum by multicolor fluorescence in situ hybridization and imaging methods. Plant Mol. Biol. 1999, 39, 1165-1173. [CrossRef] 
27. Asano, T.; Tsudzuki, T.; Takahashi, S.; Shimada, H.; Kadowaki, K. Complete nucleotide sequence of the sugarcane (Saccharum officinarum) chloroplast genome: A comparative analysis of four monocot chloroplast genomes. DNA Res. 2004, 11, 93-99. [CrossRef]

28. Júnior, T.C.; Carraro, D.M.; Benatti, M.R.; Barbosa, A.C.; Kitajima, J.P.; Carrer, H. Structural features and transcript-editing analysis of sugarcane (Saccharum officinarum L.) chloroplast genome. Curr. Genet. 2004, 46, 366-373. [CrossRef]

29. Vidigal, P.M.P.; Coelho, A.S.G.; Novaes, E.; Barbosa, M.H.P.; Peternelli, L.A. Complete chloroplast genome sequence and annotation of the Saccharum hybrid cultivar RB867515. Genome Announc. 2016, 4. [CrossRef]

30. Evans, D.L.; Joshi, S.V. Complete chloroplast genomes of Saccharum spontaneum, Saccharum officinarum and Miscanthus floridulus (Panicoideae: Andropogoneae) reveal the plastid view on sugarcane origins. Syst. Biodivers. 2016, 14, 548-571. [CrossRef]

31. Dutta, S.; Mohanty, S.; Tripathy, B.C. Role of temperature stress on chloroplast biogenesis and protein import in pea. Plant Physiol. 2009, 150, 1050-1061. [CrossRef]

32. Taylor, N.L.; Tan, Y.F.; Jacoby, R.P.; Millar, A.H. Abiotic environmental stress induced changes in the Arabidopsis thaliana chloroplast, mitochondria and peroxisome proteomes. J. Proteom. 2009, 72, 367-378. [CrossRef]

33. Ling, Q.H.; Jarvis, P. Regulation of chloroplast protein import by the ubiquitin E3 ligase SP1 is important for stress tolerance in plants. Curr. Biol. 2015, 25, 2527-2534. [CrossRef]

34. Dinha, S.N.; Sai, T.Z.T.; Nawaz, G.; Leea, K.; Kanga, H. Abiotic stresses affect differently the intron splicing and expression of chloroplast genes in coffee plants (Coffea arabica) and rice (Oryza sativa). J. Plant Physiol. 2016, 201, 85-94. [CrossRef]

35. Wang, S.; Bai, G.; Wang, S.; Yang, L.Y.; Yang, F.; Wang, Y.; Zhu, J.K.; Hua, J. Chloroplast RNA-binding protein RBD1 promotes chilling tolerance through 23S rRNA processing in Arabidopsis. PLoS Genet. 2016, 12, e1006027. [CrossRef]

36. Nawaz, G.; Lee, K.; Park, S.J.; Kim, Y.O.; Kang, H. A chloroplast-targeted cabbage DEAD-box RNA helicase BrRH22 confers abiotic stress tolerance to transgenic Arabidopsis plants by affecting translation of chloroplast transcripts. Plant Physiol. Biochem. 2018, 127, 336-342. [CrossRef]

37. Serrano, I.; Audran, C.; Rivas, S. Chloroplasts at work during plant innate immunity. J. Exp. Bot. 2016, 67, 3845-3854. [CrossRef]

38. Browse, J.; Xin, Z. Temperature sensing and cold acclimation. Curr. Opin. Plant Biol. 2001, 4, 241-246. [CrossRef]

39. Berry, J.; Bjorkman, O. Photosynthetic response and adaptation to temperature in higher plants. Annu. Rev. Plant Physiol. 1980, 31, 491-543. [CrossRef]

40. Yang, Y.; Yu, Q.; Yang, Y.; Su, Y.; Ahmad, W.; Guo, J.; Gao, S.; Xu, L.; Que, Y. Identification of cold-related miRNAs in sugarcane by small RNA sequencing and functional analysis of a cold inducible ScmiR393 to cold stress. Environ. Exp. Bot. 2018, 155, 464-476. [CrossRef]

41. Zhang, B.Q.; Yang, L.T.; Li, Y.R. Physiological and biochemical characteristics related to cold resistance in Sugarcane. Sugar Technol. 2015, 17, 49-58. [CrossRef]

42. Nogueira, F.T.; De Rosa, V.E.; Menossi, M.; Ulian, E.C.; Arruda, P. RNA expression profiles and data mining of sugarcane response to low temperature. Plant Physiol. 2003, 132, 1811-1824. [CrossRef]

43. Raubeson, L.A.; Peery, R.; Chumley, T.W.; Dziubek, C.; Fourcade, H.M.; Boore, J.L.; Jansen, R.K. Comparative chloroplast genomics: Analyses including new sequences from the angiosperms Nuphar advena and Ranunculus macranthus. BMC Genom. 2007, 8, 174. [CrossRef]

44. Wang, X.M.; Zhou, T.; Bai, G.Q.; Zhao, Y.M. Complete chloroplast genome sequence of Fagopyrum dibotrys: Genome features, comparative analysis and phylogenetic relationships. Sci. Rep. 2018, 8, 12379. [CrossRef]

45. Dong, W.P.; Xu, C.; Li, C.H.; Sun, J.H.; Zuo, Y.J.; Shi, S.; Cheng, T.; Guo, J.J.; Zhou, S.L. Ycf1, the most promising plastid DNA barcode of land plants. Sci. Rep. 2015, 5, 8348. [CrossRef]

46. Wang, C.L.; Ding, M.Q.; Zou, C.Y.; Zhu, X.M.; Tang, Y.; Zhou, M.L.; Shao, J.R. Comparative analysis of four buckwheat species based on morphology and complete chloroplast genome sequences. Sci. Rep. 2017, 7, 6514. [CrossRef]

47. Song, Y.; Dong, W.P.; Liu, B.; Xu, C.; Yao, X.; Gao, J.; Corlett, R.T. Comparative analysis of complete chloroplast genome sequences of two tropical trees Machilus yunnanensis and Machilus balansae in the family Lauraceae. Front. Plant Sci. 2015, 6, 662. [CrossRef] 
48. Chung, H.J.; Jung, J.D.; Park, H.W.; Kim, J.H.; Cha, H.W.; Min, S.R.; Jeong, W.J.; Liu, J.R. The complete chloroplast genome sequences of Solanum tuberosum, and comparative analysis with Solanaceae species identified the presence of a 241-bp deletion in cultivated potato chloroplast DNA sequence. Plant Cell Rep. 2006, 25, 1369-1379. [CrossRef]

49. Xue, Z.Q.; Xue, J.H.; Victorovna, K.M.; Ma, K.P. The complete chloroplast DNA sequence of Trapa maximowiczii Korsh. (Trapaceae), and comparative analysis with other Myrtales species. Aquat. Bot. 2017, 143, 54-62. [CrossRef]

50. Saski, C.; Lee, S.B.; Fjellheim, S.; Guda, C.; Jansen, R.K.; Lou, H.; Tomkins, J.; Rognli, O.A.; Daniell, H.; Clarke, J.L. Compete chloroplast genome sequences of Hordeum vulgare, Sorghum bicolor and Agrostis stolonifera, and comparative analysis with other grass genomes. Theo. Appl. Genet. 2007, 115, 571-590. [CrossRef]

51. Park, I.; Yang, S.Y.; Kim, W.J.; Noh, P.; Lee, H.O.; Moon, B.C. The complete chloroplast genomes of six Ipomoea species and Indel marker development for the discrimination of authentic pharbitidis semen (seeds of I. nil or I. purpurea). Front. Plant Sci. 2018, 9, 965. [CrossRef]

52. Nguyen, V.B.; Giang, V.N.L.; Waminal, N.E.; Park, H.S.; Kim, N.H.; Jang, W.; Lee, J.; Yang, T.J. Comprehensive comparative analysis of chloroplast genomes from seven Panax species and development of an authentication system based on species-unique single nucleotide polymorphism markers. J. Ginseng Res. 2018. [CrossRef]

53. Li, Y.T.; Zhang, J.; Li, L.F.; Gao, L.J.; Xu, J.T.; Yang, M.S. Structural and comparative analysis of the complete chloroplast genome of Pyrus hopeiensis—“wild plants with a tiny population" —and three other Pyrus species. Int. J. Mol. Sci. 2018, 19, 3262. [CrossRef]

54. Provan, J.; Powell, W.; Hollingsworth, P.M. Chloroplast microsatellites: New tools for studies in plant ecology and evolution. Trends Ecol. Evol. 2001, 16, 142-147. [CrossRef]

55. Holaday, A.S.; Martindale, W.; Alred, R.; Brooks, A.L.; Leegood, R.C. Changes in activities of enzymes of carbon metabolism in leaves during exposure of plants to low temperature. Plant Physiol. 1992, 98, 1105-1114. [CrossRef]

56. Mohanty, S.; Grimm, B.; Tripathy, B.C. Light and dark modulation of chlorophyll biosynthetic genes in response to temperature. Planta 2006, 224, 692-699. [CrossRef]

57. Tewari, A.K.; Tripathy, B.C. Acclimation of chlorophyll biosynthetic reactions to temperature stress in cucumber (Cucumis sativus L.). Planta 1999, 208, 431-437. [CrossRef]

58. Allen, D.J.; Ort, D.R. Impact of chilling temperatures on photosynthesis in warm-climate plants. Trends Plant Sci. 2001, 6, 36-42. [CrossRef]

59. Govindacharya, S.; Bukhov, N.G.; Joly, D.; Carpentier, R. Photosystem II inhibition by moderate light under low temperature in intact leaves of chilling-sensitive and tolerant plants. Physiol. Plant 2004, 121, 322-333. [CrossRef]

60. Huner, N.P.A.; Öquist, G.; Hurry, V.M.; Krol, M.; Falk, S.; Griffith, M. Photosynthesis, photoinhibition and low temperature acclimation in cold tolerant plants. Photosynth. Res. 1993, 37, 19-39. [CrossRef]

61. Wise, R.R.; Olson, A.J.; Schrader, S.M.; Sharkey, T.D. Electron transport is the functional limitation of photosynthesis in field-grown Pima cotton plants at high temperature. Plant Cell Environ. 2004, 27, 717-724. [CrossRef]

62. Yu, J.Q.; Zhou, Y.H.; Huang, L.F.; Allen, D. Chill-induced inhibition of photosynthesis: Genotypic variation within Cucumis sativus. Plant Cell Physiol. 2002, 43, 1182-1188. [CrossRef]

63. Zhou, Y.H.; Yu, J.Q.; Mao, W.H.; Huang, L.F.; Song, X.S.; Nogue's, S. Genotypic variation of Rubisco expression, photosynthetic electron flow and antioxidant metabolism in the chloroplasts of chill-exposed cucumber plants. Plant Cell Physiol. 2006, 47, 192-199. [CrossRef]

64. Yang, Y.; Gao, S.; Jiang, Y.; Lin, Z.; Luo, J.; Li, M.; Guo, J.; Su, Y.; Xu, L.; Que, Y. The physiological and agronomic responses to nitrogen dosage in different sugarcane varieties. Front. Plant Sci. 2019, 10, 406. [CrossRef]

65. Doyle, J.J. A rapid DNA isolation procedure for small quantities of fresh leaf tissue. Phytochem. Bull. 1987, 19, 11-15.

66. Tillich, M.; Lehwark, P.; Pellizzer, T.; Ulbricht-Jones, E.S.; Fischer, A.; Bock, R.; Greiner, S. GeSeq-versatile and accurate annotation of organelle genomes. Nucleic Acids Res. 2017, 45, 6-11. [CrossRef]

67. Kimura, M.A. simple method for estimating evolutionary rates of base substitutions through comparative studies of nucleotide sequences. J. Mol. Evol. 1980, 16, 111-120. [CrossRef] 
68. Wang, D.; Zhang, Y.; Zhang, Z.; Zhu, J.; Yu, J. KaKs_Calculator 2.0: A toolkit incorporating gamma-seriesmethods and sliding window strategies. Genom. Proteom. Bioinform. 2010, 8, 77-80. [CrossRef]

69. Melotto-Passarin, D.M.; Tambarussi, E.V.; Dressano, K.; De Martin, V.F.; Carrer, H. Characterization of chloroplast DNA microsatellites from Saccharum spp and related species. Genet. Mol. Res. 2011, 10, 2024-2033. [CrossRef]

70. Dinh, T.H.; Watanabe, K.; Takaragawa, H.; Nakabaru, M.; Kawamitsu, Y. Photosynthetic response and nitrogen use efficiency of sugarcane under drought stress conditions with different nitrogen application levels. Plant Prod. Sci. 2017, 20, 412-422. [CrossRef]

71. Shu, S.; Tang, Y.Y.; Yuan, Y.H.; Sun, J.; Zhong, M.; Guo, S.R. The role of 24-epibrassinolide in the regulation of photosynthetic characteristics and nitrogen metabolism of tomato seedlings under a combined low temperature and weak light stress. Plant Physiol. Biochem. 2016, 107, 344-353. [CrossRef]

C 2019 by the authors. Licensee MDPI, Basel, Switzerland. This article is an open access article distributed under the terms and conditions of the Creative Commons Attribution (CC BY) license (http://creativecommons.org/licenses/by/4.0/). 